\title{
Contribution of Nitrogen Sources to Streams in Mixed-use Watershed Varies Seasonally in a Temperate Region
}

\section{Zuhong Lin}

Beijing University of Chemical Technology

Junchi Liu

Institute of Vertebrate Paleontology and Paleoanthropology Chinese Academy of Sciences

\section{Yong Xiao}

Beijing University of Chemical Technology

\section{Chaojie Yu}

Beijing University of Chemical Technology

\section{Jinlan Zhang}

Beijing University of Chemical Technology

\section{Tingting Zhang ( $\nabla$ zhangtt@mail.buct.edu.cn )}

Beijing University of Chemical Technology https://orcid.org/0000-0001-5249-2201

\section{Research Article}

Keywords: Nitrate isotope, Land-use, Source apportionment, SIAR, Beijing-Tianjin-Hebei region

Posted Date: June 3rd, 2021

DOI: https://doi.org/10.21203/rs.3.rs-448636/v1

License: (c) (i) This work is licensed under a Creative Commons Attribution 4.0 International License. Read Full License

Version of Record: A version of this preprint was published at Environmental Science and Pollution Research on November 4th, 2021. See the published version at https://doi.org/10.1007/s11356-02116930-8. 


\section{Contribution of nitrogen sources to streams in mixed-use}

\section{2 watershed varies seasonally in a temperate region}

4 Zuhong Lin ${ }^{\mathrm{a}}$, Junchi Liu ${ }^{\mathrm{b}}$, Yong Xiao ${ }^{\mathrm{a},{ }^{*}}$, Chaojie $\mathrm{Yu}^{\mathrm{a}}$, Jinlan Zhang ${ }^{\mathrm{a}}$, Tingting Zhang, ${ }^{\mathrm{a}, \#}$ 5

${ }^{\text {a }}$ Department of Environmental Science and Engineering, Research Centre for Resource and Environment, Beijing University of Chemical Technology, Beijing 100029, People's Republic of China

${ }^{\mathrm{b}}$ Key Laboratory of Vertebrate Evolution and Human Origins, Institute of Vertebrate Paleontology and Paleoanthropology, Chinese Academy of Sciences, Beijing 100044, People's Republic of China

* Corresponding authors.

E-mail addresses: * xiaoyong@mail.buct.edu.cn (Xiao Y);

\# zhangtt@mail.buct.edu.cn (Zhang T). 


\section{Abstract}

The Beiyun river flows through a hot spot region of Beijing-Tianjin-Hebei in China that serves a majority of occupants. However, the region experiences severe nitrate pollution, posing a threat to human health due to inadequate self-purification capacity. In that context, there is an urgent need to assess nitrate levels in this region. Herein, we used $\delta^{15} \mathrm{~N}-\mathrm{NO}_{3}, \delta^{18} \mathrm{O}-\mathrm{NO}_{3}$ isotopes analysis, and stable isotope analysis model to evaluate the nitrate source apportionment in the Beiyun river. A meta-analysis was then used to compare the potential similarity of nitrate sources among the Beiyun riverine watershed and other watersheds. Results of nitrate source apportionment revealed that nitrate originated from the manure \& sewage (contribution rate: $89.6 \%$ ), soil nitrogen (5.9\%), and nitrogen fertilizer (3.9\%) in the wet season. While in the dry season, nitrate mainly originated from manure \& sewage (91.6\%). Further, different land-use types exhibited distinct nitrate compositions. Nitrate in urban and suburban areas mostly was traced from manure \& sewage (90.5\% and $78.8 \%$, respectively). Notably, the different nitrate contribution in the rural-urban fringe and plant-covered areas were manure \& sewage $(44.3 \%$ and $32.8 \%)$, soil nitrogen $(26.9 \%$ and $35.7 \%)$, nitrogen fertilizer (23.5\% and 29.4\%), and atmospheric deposition (5.3\% and 2.0\%). Through a meta-analysis, we found nitrogen fertilizer, soil nitrogen, and manure \& sewage as the main nitrate sources in the Beiyun riverine watershed or the other similar complex watersheds in the temperate. Thus, this study provides a scientific basis for nitrate source apportionment and nitrate preventive management in watersheds with complex land-use types in temperate regions.

\section{Keywords}

Nitrate isotope; Land-use; Source apportionment; SIAR; Beijing-Tianjin-Hebei region 


\section{Introduction}

Excess loads of nitrate occur due to population growth and extensive human activities (Jiang et al., 2021), causing eutrophication of the water environment. Nitrates then get into the human body along the food chain, resulting in methemoglobinemia in newborns or stomach cancer (Zhang et al., 2018b; Li et al., 2019). Therefore, increasing interest has been geared towards controlling or preventing nitrate from ending up in the water (Hu et al., 2019). Similarly, the need for tracing the source of nitrate in the river has heightened.

Based on the current understanding, tracing the source of nitrate in the river is a topical issue. Nitrate contains stable natural isotopes of $\delta^{15} \mathrm{~N}-\mathrm{NO}_{3}$ and $\delta^{18} \mathrm{O}-\mathrm{NO}_{3}$, which has become a favorable premise for adopting isotope technique to identify nitrate pollution sources in the river (Jani and Toor, 2018). However, the obtained isotopic values may overlap when using dual nitrate isotopes to trace the source of nitrate ( $\mathrm{Li}$ et al., 2019). The accuracy of traceability can be greatly improved using certain statistical methods or simulating models. For example, principal component analysis and cluster analysis could connect environmental factors (hydrochemical compositions) with social variables (e.g., population density, village percentage, or land-use type) to classify nitrate sources (Ma et al., 2015; Li et al., 2019). To obtain a more accurate nitrate source apportionment result, determining the contribution ratio of each source after source trace is necessary. Notably, stable isotope analysis in the R (SIAR) model has been proved as an excellent and flexible model in estimating the proportional contributions of nitrate sources. It not only can perform quantitative calculations between different sources (e.g., atmospheric deposition, soil nitrogen, nitrogen fertilizer, and manure \& sewage), but also provide an estimate between different river locations (e.g., surface and underground water, or rivers in different areas) (Yi et al., 2017; Hu et al., 2019; 
Jiang et al., 2021).

Nitrate source is closely linked with human behaviors and the characteristics of watersheds (e.g., the climate and land-use type) (Hu et al., 2019; Ma et al., 2019). It is challenging to trace the source of nitrate in complex watersheds because, in such areas, the pollution sources show variability with the spatiotemporal variation (Yi et al., 2017; Hu et al., 2019; Li et al., 2019). Besides, it is more difficult to get reliable universal source analytic conclusions from single research. Therefore, to obtain a more general pattern of pollution sources, a meta-analysis is adopted as a quantitative analytic method (Wang et al., 2021). It can give a comparison of the target watershed with other watersheds to generate a reliable source apportionment conclusion. The Beiyun riverine is a complex watershed linked to Beijing, Tianjin, and Hebei Province, characterized by multiple land-use types and incorporated with various economic structures. Nitrate pollution inevitably rose due to the development of urbanization in the watershed and might be harmful to the inhabitants (Zhang et al., 2020a). Although tracing the nitrate source is necessary, the complex watershed factors make the entire process challenging, because most of the water in the Beiyun riverine watershed comes from the WWTPs, and the land-use type and human social activities around the river are complex (Zhang et al., 2021). Due to the large amount of WWTPs emission, the nitrate in the basin is likely to come from manure $\&$ sewage source, but at the same time, the contribution of other sources should also be considered.

This present work mainly purposed to determine the source, migration, and transformation of nitrate in the Beiyun riverine watershed by analyzing the $\delta^{15} \mathrm{~N}^{-\mathrm{NO}_{3}}$ and $\delta^{18} \mathrm{O}_{-} \mathrm{NO}_{3}$ values. We calculated the contribution ratio of nitrate at each nitrate source using the SIAR model. Samples were collected from 26 sites located in Beijing, Tianjin, and Hebei in the mainstream and tributaries of the whole Beiyun riverine 
watershed in the wet and dry seasons for four months. Mechanistically, we performed a meta-analysis of regions with similar geographical characteristics to the Beiyun riverine watershed and analyzed the various sources of nitrate under different climate and land-use types. Of note, the resolution of traceability had been improved through multiple statistical analyses.

\section{Materials and Methods}

\subsection{Study area and sampling design}

The Beiyun riverine watershed is located in a hotspot region of urbanization in the Beijing-Tianjin-Hebei region with complex land-use types and economic structures. Due to a shortage of water resources, wastewater from the WWTPs is imported to supplement the river course (Zhang et al., 2021). The whole watershed area is about $6166 \mathrm{~km}^{2}$. The mountainous area and a vast forest cover the riverine source of the upstream which accounts for $16 \%$ and $8.7 \%$ of the watershed, respectively. The remaining area is plains, which consist of dry land and construction land (Fig. 1a), and the plain area is mainly composed of alluvial-diluvial fans along rivers (Wu et al., 2020). The upstream tributaries are the urban area of Beijing. The mainstream and tributaries of the downstream are dry land with villages in Tianjin and Hebei province (Liu et al., 2018; Zhang et al., 2020). Land-use data came from the Computer Network Information Center, Chinese Academy of Sciences (www.gscloud.cn). And the detailed hydrology and climate information are shown in SI. 

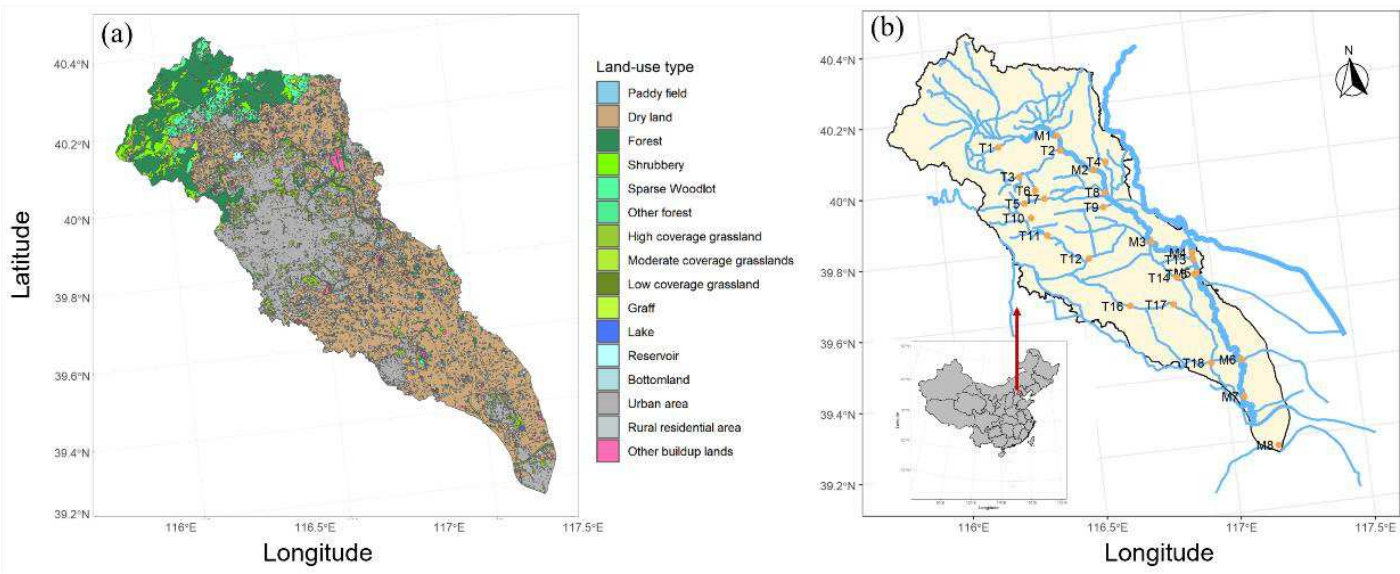

Fig.1. Study area and sampling sites in the Beiyun riverine watershed.

A total of 26 sampling sites were selected in the Beiyun riverine watershed (Fig. 1b). They covered most of the land-use types in the humanities and natural environment. Specific information about the sampling sites is listed in Table S1. Sampling was conducted in June and September 2019 (wet season) and in November 2019 and January 2020 (dry season). We conducted grab sampling in the central part of each river.

\subsection{Water quality analysis}

The collected water samples were filtered through pre-combusted and preweighed glass fiber filters (Whatman, GF/F, $47 \mathrm{~mm}$ in diameter, GE, UK), and stored at $4^{\circ} \mathrm{C}$ for subsequent analyses. Measurements of $\mathrm{pH}$, dissolved oxygen (DO), and electrical conductivity (EC) were taken in situ using the YSI electrode (Xylem Company, New York, USA). The $\mathrm{NO}_{3}-\mathrm{N}, \mathrm{NO}_{2}-\mathrm{N}, \mathrm{NH}_{4}-\mathrm{N}$, and $\mathrm{TN}$ were detected using a UV-visible spectrophotometer (HACH DR 2800, USA). We conducted an ion chromatography (IC) system 90 (Dionex Corp, Sunnyvale, CA, USA) to measure the $\mathrm{Cl}^{-}$, with a precision below $5 \%$.

Dual nitrate isotopes were tested in the Institute of Vertebrate Paleontology and Paleoanthropology, Chinese Academy of Sciences. The collection of dual nitrate isotopes was based on the ion-exchange method (Silva et al., 2000), which transferred 
$151 \quad X_{i j}=\sum_{k=1}^{k} p_{k}\left(S_{j k}+C_{j k}\right)+\varepsilon_{i j}$ delta notation. respectively.

\subsection{SIAR modeling} were as follows:

$$
S_{j k} \sim N\left(\mu_{j k}, \omega_{j k}^{2}\right)
$$

$$
C_{j k} \sim N\left(\lambda_{j k}, \tau_{j k}^{2}\right)
$$

$\varepsilon_{j k} \sim N\left(0, \sigma_{k}^{2}\right)$

the dissolved $\mathrm{NO}_{3}-\mathrm{N}$ in water into the solid $\mathrm{AgNO}_{3}$. Then, $\mathrm{AgNO}_{3}$ was analyzed for $\delta^{15} \mathrm{~N}-\mathrm{NO}_{3}$ and $\delta^{18} \mathrm{O}-\mathrm{NO}_{3}$ using a Flash $2000 \mathrm{HT}$ and Fisher 253 Plus continuous flow isotope ratio mass spectrometer (Thermo, USA), which was equipped the constant flow device Conflo IV. The $\delta^{15} \mathrm{~N}-\mathrm{NO}_{3}$ value was reported in parts per thousand or per mil (\%o) relative to the atmospheric $\mathrm{N}_{2}$ and $\mathrm{CO}$ isotopic standard. The international isotopic reference material USGS $25\left(\delta^{15} \mathrm{~N}=-30.4 \%\right.$, air $\left.\mathrm{N}_{2}\right)$, USGS $42\left(\delta^{18} \mathrm{O}=+8.56 \%\right.$, VSMOW), EMA P2 $\left(\delta^{18} \mathrm{O}=+26.88 \%\right.$, VSMOW $)$, IAEA-NO $\mathrm{NO}_{3}\left(\delta^{15} \mathrm{~N}=+4.7 \%\right.$, air $\mathrm{N}_{2}$, $\delta^{18} \mathrm{O}=+25.6 \%$, VSMOW) were measured to monitor analytical accuracy. The standard deviation for duplicate analysis was less than $\pm 0.2 \%$ for $\delta^{15} \mathrm{~N}_{-\mathrm{NO}_{3}}$ and less than $\pm 0.4 \%$ o for $\delta^{18} \mathrm{O}-\mathrm{NO}_{3}$. Stable isotope ratios were reported in per mil (\%o) using the conventional

$\delta_{\text {sample }}(\%)=\left(\frac{R_{\text {sample }}}{R_{\text {standard }}}-1\right) \times 1000(\%$ o $)$

Notably, $\delta_{\text {sample }}$ denoted the stable isotope ratio in the water samples. $R_{\text {sample }}$ and

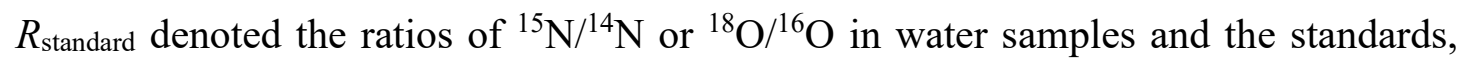

The stable isotope analysis in the R (SIAR) model was adopted to estimate the contributions of multiple nitrate sources in individual water samples. The equations 
Where $X_{i j}$ denotes the isotope value $j$ of the water sample $i(i=1,2,3, \ldots, i$ and $j=$

$1,2,3, \ldots, j) . S_{j k}$ denotes the source value $k$ on isotope $j(k=1,2,3, \ldots, k)$ and is normally distributed with mean $\mu_{j k}$ and standard deviation $\omega_{j k} . p_{k}$ denotes the proportion of source $k$, estimated by the SIAR model. $C_{j k}$ denotes the fractionation factor for isotope $j$ of source $k$ and is normally distributed with mean $\lambda_{j k}$ and standard deviation $\tau_{j k} . \varepsilon_{j k}$ denotes the residual error, representing additional unquantified variation between individual samples and is normally distributed with mean 0 and standard deviation $\sigma_{j}$. A more detailed description of the SIAR model can be found elsewhere (Jackson et al., 2019). In this study, $\delta^{15} \mathrm{~N}-\mathrm{NO}_{3}$ and $\delta^{18} \mathrm{O}-\mathrm{NO}_{3}(j=2)$ values were applied to estimate the contribution of four predefined sources, including atmospheric deposition, fertilizer nitrification, soil nitrogen, and manure \& sewage. The mean and standard deviation of each source was cited from literature, as indicated in Table S2 (Liu et al., 2018). The fractionation factors for all sources were set as zero $\left(C_{j k}=0\right)$ in the condition of the surface river (Jiang et al., 2021). Using the Kolmogorov-Smirnoff test, we examined the normality of potential source values.

\subsection{Statistical analysis}

One-way ANOVA analysis was used to test the differences in hydrochemical indicators between seasons and sites. Differences were considered significant for $p$ values less than 0.05 . With cluster analysis, we used the squared Euclidean metric with Ward's method to explore the possible similar correlation of different nitrogen indicators and the land-use type among sites to sites. The raw data set was standardized to avoid incorrect clustering because different indicators had massively varying dimensions and units. The heatmap of cluster analysis revealed stronger similarity between the sites, the closer the matrix distance between them, and the bluer the color. Furthermore, for correlation analysis of different hydrochemical indicators, we used the 
Pearson test by corrplot package in R. The correlation coefficient was reflected in different colors. Pearson test was used for all linear regressions.

To disentangle the impact of different factors such as the condition of temperate continental monsoon climate (CMC), complex urban and rural environment (CURE) on each nitrate source. A meta-analysis based on a linear mixed model was conducted (lme4 package in $\mathrm{R}$ was used to operate all the calculations). The relationship equation in linear mixed model was as follows:

Result $<-\operatorname{lmer}(\ln (R R)$. Source $\sim$ 'fixed variables $1+$ fixed variables $2+\ldots$ ' 'fixed variables $1 \times$ fixed variables $2 \times \ldots+(1 \mid$ random factor $)$, Weights $=w t$. Source $)$

Where Result is a final effect value 'In (RR)' of condition CMC or CURE. In (RR). Source are each $\ln (\mathrm{RR})$ values of nitrogen fertilizer, soil nitrogen and manure \& sewage, which calculation equation is equation (1) in SI. fixed variables $1,2, \ldots$ include the type of CURE/CMC and its corresponding $\delta^{15} \mathrm{~N}^{-N} \mathrm{O}_{3}$ value in each nitrate source. random factor is the number of samples included in this study, which can eliminate the autocorrelation within the same study. Weights are the weighting coefficient of the number of samples included in this study, which calculation equation is equation (2) in SI. All the statistical analyses were performed using R, version 3.6.3.

\section{Results and discussion}

\subsection{Spatiotemporal variations of nitrate}

The concentrations of dissolved inorganic nitrogen and nitrate isotope values at each site in the main streams $(n=8)$ and tributaries $(n=18)$ of the watershed are shown in Fig. 1. The average concentration of $\mathrm{NO}_{2}-\mathrm{N}$ and $\mathrm{NH}_{4}-\mathrm{N}$ was lower than $0.20 \mathrm{mg} \mathrm{L}^{-1}$ and $1.5 \mathrm{mg} \mathrm{L}^{-1}$ (Fig. 2a, 2b) in the wet and dry seasons, respectively. However, $\mathrm{NO}_{3}-\mathrm{N}$ and TN in two seasons exceeded $5.0 \mathrm{mg} \mathrm{L}^{-1}$ (Fig. 2c, 2d), which was sufficient to cause eutrophication of surface water. The average concentration of $\mathrm{NO}_{3}-\mathrm{N}$ was $6.5 \mathrm{mg} \mathrm{L}-1$ 
and $8.3 \mathrm{mg} \mathrm{L}^{-1}$ in the wet and dry season, respectively (Fig. 2c), which had exceeded the grade V of China surface water environmental quality standard (GB3838-2002). Of note, in all seasons, $\mathrm{NO}_{3}-\mathrm{N}$ was the main form of the nitrogen in the Beiyun river (Fig. S4). For $\delta^{15} \mathrm{~N}$ and $\delta^{18} \mathrm{O}-\mathrm{NO}_{3}$, the $\delta^{15} \mathrm{~N}-\mathrm{NO}_{3}$ value mainly fluctuated between $0.6 \%$ to 26\% (Fig. 2e). The mean value in the wet season and dry season was $15.1 \pm 5.1 \%$ and $14.4 \pm 2.9 \%$, respectively. And the $\delta^{18} \mathrm{O}-\mathrm{NO}_{3}$ value mainly fluctuated between $-13.3 \%$ to $9.9 \%$ (Fig. $2 \mathrm{f}$ ). The mean value in the wet season and the dry season was $0.6 \pm 2.9 \%$ o and $-5.6 \pm 3.3 \%$, respectively. Through ANOVA analysis, we revealed that from the temporal perspective, the concentration of $\mathrm{NH}_{4}-\mathrm{N}, \mathrm{NO}_{3}-\mathrm{N}$, and $\mathrm{TN}$ was not significantly different $(p>0.05)$ except $\mathrm{NO}_{2}-\mathrm{N}(p<0.05)$, which might be attributed to the varying conversion reaction of nitrogen in different seasons (Zhang et al., 2018a). From the spatial aspect, $\mathrm{NH}_{4}-\mathrm{N}, \mathrm{NO}_{3}-\mathrm{N}$, and $\mathrm{TN}$ concentration were still not significant $(p>0.05)$, but $\mathrm{NO}_{2}-\mathrm{N}$ concentration showed significant difference $(p<0.05)$ in tributaries, which could be due to different pollution sources in the tributaries being more complex than the mainstream (Yi et al., 2017). And neither $\delta^{15} \mathrm{~N}-\mathrm{NO}_{3}$ nor $\delta^{18} \mathrm{O}-\mathrm{NO}_{3}$ value showed a significant spatiotemporal difference in the main streams and tributaries $(p>0.05)$. However, it is too limited to discuss the difference of isotope values only from the main streams and the tributaries. Therefore, the discussion of different land use types was carried out in section 3.2 and 3.3 . 

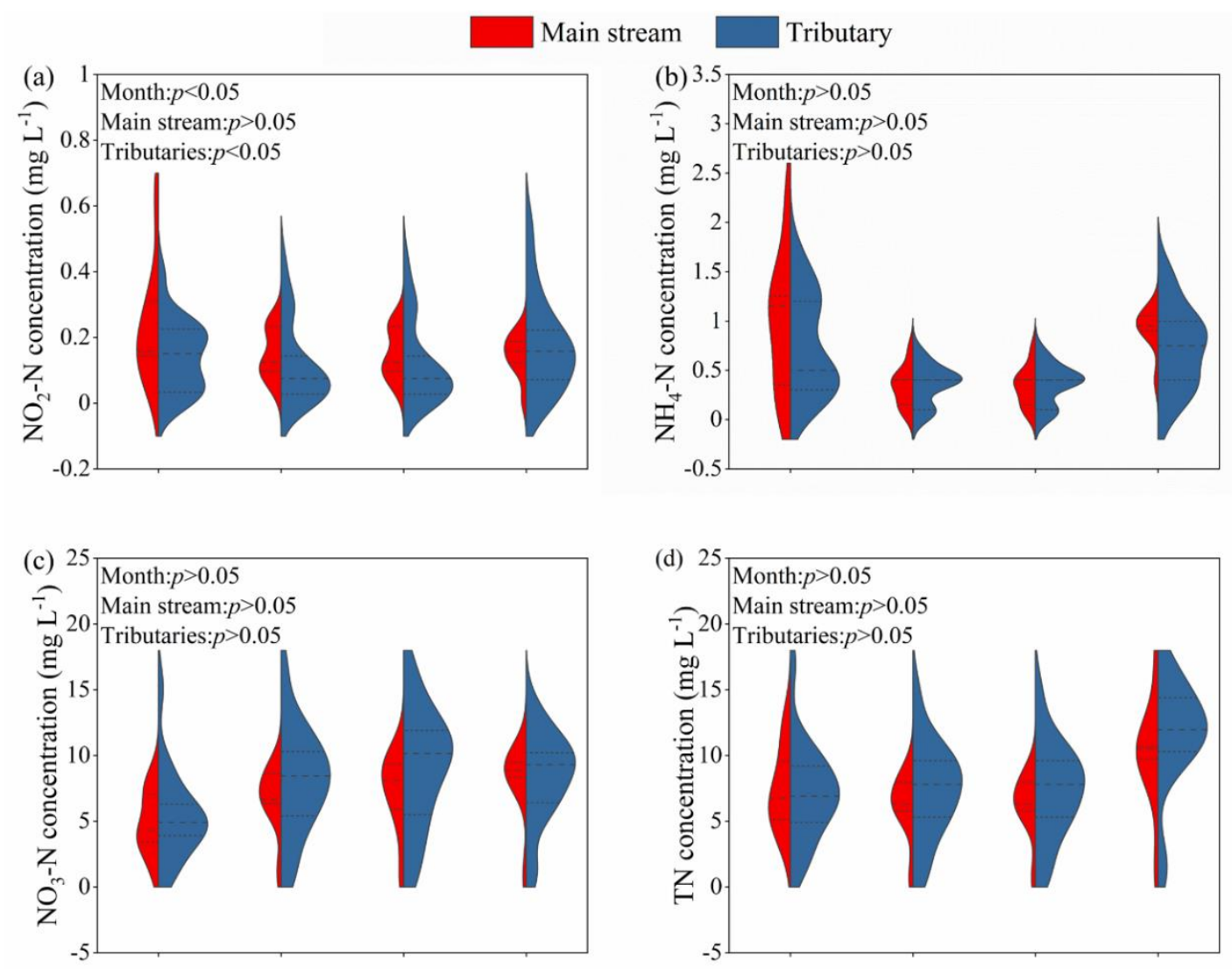

(e) ${ }^{40}$ Month: $p>0.05$
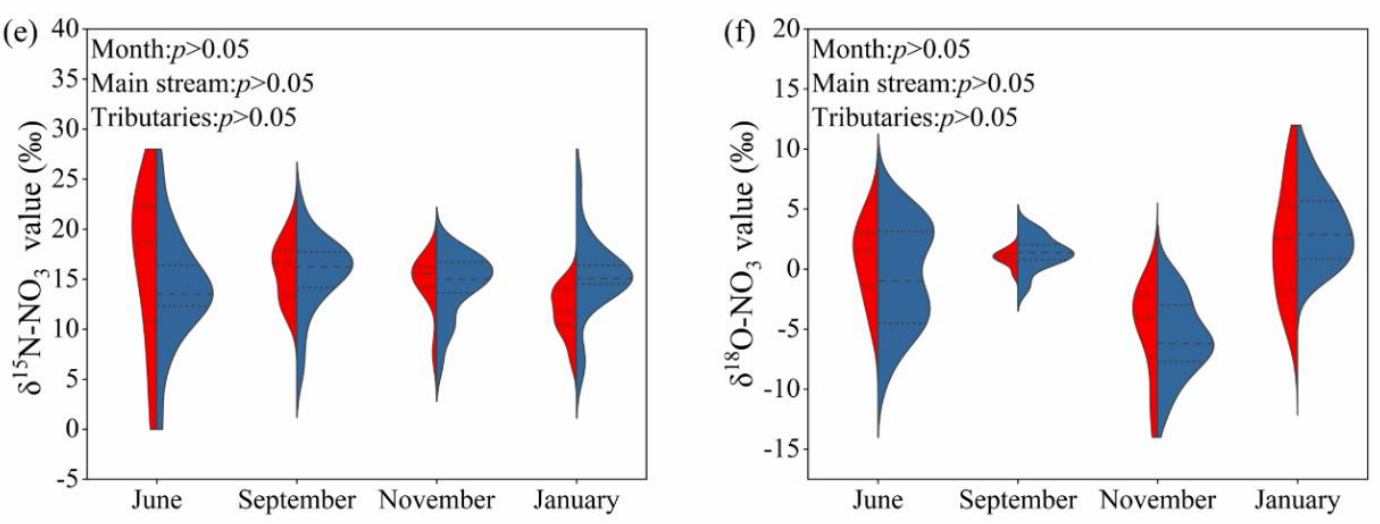

Fig. 2. Spatiotemporal variations of inorganic nitrogen and nitrate isotopes (a) $\mathrm{NO}_{2}-\mathrm{N}$ (b)

$\mathrm{NH}_{4}-\mathrm{N}(\mathrm{c}) \mathrm{NO}_{3}-\mathrm{N}$ (d) $\mathrm{TN}$ (e) $\delta^{15} \mathrm{~N}-\mathrm{NO}_{3}$ (f) $\delta^{18} \mathrm{O}-\mathrm{NO}_{3}$. Dashed are the median line, dotted are

the lines of upper and lower quartiles, and the monitoring data points are concentrated in

The Pearson correlation of nitrate isotopes and other hydrochemical indicators is presented in Fig. 3. In the wet season (Fig. 3a), $\mathrm{NO}_{3}-\mathrm{N}$ had was positively correlated with $\mathrm{NO}_{2}-\mathrm{N}, \mathrm{TN}$ and $\mathrm{Cl}^{-}$, but it had a negative correlation with $\mathrm{DO}$ and $\delta^{15} \mathrm{~N}-\mathrm{NO}_{3}$. Additionally, $\delta^{15} \mathrm{~N}-\mathrm{NO}_{3}$ showed a positive correlation with $\mathrm{NO}_{2}-\mathrm{N}$, whereas it showed 
a negative correlation with $\mathrm{NH}_{4}-\mathrm{N}$ and DO. There are two possibilities for this result: (I) In the wet season, nitrification process transformed $\mathrm{NH}_{4}-\mathrm{N}$ into $\mathrm{NO}_{2}-\mathrm{N}$. Then, $\mathrm{NO}_{2}-$ $\mathrm{N}$ was oxidized into $\mathrm{NO}_{3}-\mathrm{N}$ under the high $\mathrm{DO}$ condition (Liu et al., 2018). In comparison, denitrification consumed $\mathrm{NO}_{3}-\mathrm{N}$, thereby increased the $\delta^{15} \mathrm{~N}-\mathrm{NO}_{3}$ value (Yang and Toor, 2016; Bu et al., 2017). (II) For continuous anthropogenic emissions, the amount of sewage discharged during the wet season was greater, which leaded to stronger correlations between indicators. Notably, $\mathrm{Cl}^{-}$is usually found in sewage, and high $\mathrm{NO}_{3}-\mathrm{N}$ concentration is usually accompanied by high $\mathrm{Cl}^{-}$concentration (Yi et al., 2018).

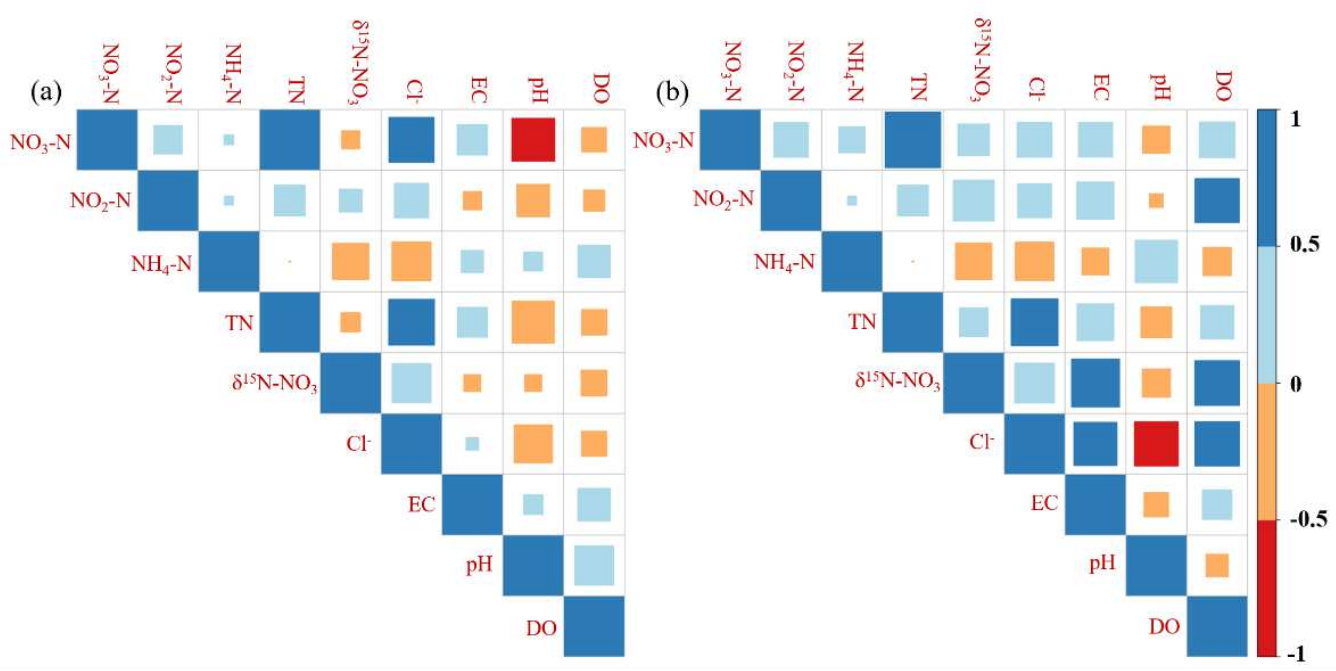
2017; Ma et al., 2019). The high correlation between $\mathrm{NO}_{3}-\mathrm{N}$ and $\mathrm{Cl}^{-}$in the wet season also indicated that the amount of sewage discharged in the wet season was large. And for a detailed discussion of $\mathrm{Cl}^{-}$can be seen at section 3.2.1. However, in the dry season (Fig. 3b), $\mathrm{NO}_{3}-\mathrm{N}$ was positively correlated with $\mathrm{DO}$ and $\delta^{15} \mathrm{~N}-\mathrm{NO}_{3}$. On the other hand, $\delta^{15} \mathrm{~N}-\mathrm{NO}_{3}$ was positively correlated with $\mathrm{NO}_{2}-\mathrm{N}$ and $\mathrm{DO}$, while it was negatively correlated with $\mathrm{NH}_{4}-\mathrm{N}$. These results were contrary to those in the wet season, which might be due to the lack of obvious denitrification during the dry season (Liu et al., 


\subsection{Source apportionment of nitrate}

253

254

255

\subsubsection{Source apportionment of nitrate by isotopes and stable chemical} ion

The nitrate sources in different seasons and different branches are shown in Fig. 4. Source apportionment of nitrate was obtained via isotope fractionation (Jani and Toor 2018). Different nitrate sources showed different ranges of dual-isotope values (Fig. 4), including atmospheric deposition, $\mathrm{NO}_{3}$-fertilizer, $\mathrm{NH}_{4}$-fertilizer, soil nitrogen, and manure \& sewage. The value of $\delta^{15} \mathrm{~N}^{-N_{3}} 3$ ranged between $+0.6 \%$ to $+26.0 \%$ and $+6.0 \%$ o to $+24.7 \%$ in the wet season and the dry season, respectively. Besides, the value of $\delta^{18} \mathrm{O}-\mathrm{NO}_{3},-8.6 \%$ to $+5.3 \%$ and $-13.3 \%$ to $+9.9 \%$ in the wet season and the dry season, respectively. In the wet season, the nitrate originated from $\mathrm{NH}_{4}$-fertilizer, soil nitrogen, and manure \& sewage, whereas they originated from manure \& sewage in the dry season.

The fluctuating nitrate dual-isotope values were attributed to human activities and climatic changes. For instance, in the wet season, fertilizers were frequently used for agriculture in the watershed (Peters et al., 2019). A lot of nitrogen-containing soil particulates were flushed into the water aided by soil erosion (Li et al., 2019). Thus, fertilizer and soil nitrogen sources are considered to occur mainly in the wet season rather than in the dry season. In the dry season, all nitrate was traced from manure \& sewage. Of note, the atmospheric deposition source did not show significant influence in both two seasons. A high $\delta^{18} \mathrm{O}-\mathrm{NO}_{3}$ value usually appears in rainfall rather than the surface river (Hu et al., 2019), and the contribution of precipitation to surface water was, in most cases, low in the temperate watersheds. (Liu et al., 2018; Kruk et al., 2020). 


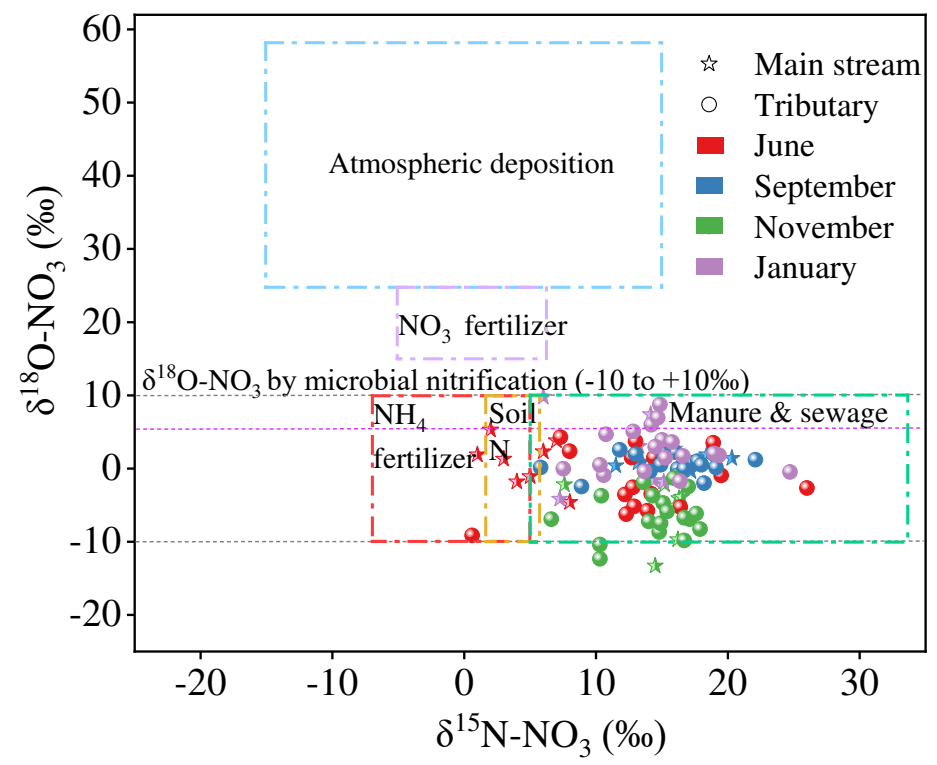

Fig. 4. Nitrate isotopic value in the Beiyun river together with typical nitrate isotope source members. The theoretical $\delta^{18} \mathrm{O}-\mathrm{NO}_{3}$ value of nitrification was in the range of $-10 \%$ to $5.7 \%$ (Li et al., 2014a; Liu et al., 2018). The various nitrate isotope sources in the plot are adapted from previous studies (Shin et al., 2013; Jani and Toor, 2018).

Furthermore, the microbial reaction contributed to the fluctuation of nitrate dual281 isotope values. Nitrification and denitrification were essential in the occurrence and characteristics of the nitrate in the river ecosystem (Yang and Toor, 2016). In general, microorganisms preferentially generate $\delta^{14} \mathrm{~N}^{-\mathrm{NO}_{3}}$ in the nitrification process, this explains why the measured value of $\delta^{15} \mathrm{~N}^{-N}{ }_{3}$ was low (Zhang et al., 2020b). $\delta^{18} \mathrm{O}$ $\mathrm{NO}_{3}$ in the nitrification process could be described by equation (7) (Li et al., 2019; Fadhullah et al., 2020). Based on previous calculations (Li et al., 2014a; Liu et al., 2018). the theoretical $\delta^{18} \mathrm{O}-\mathrm{NO}_{3}$ value of nitrification in the Beiyun river was $-10 \%$ o to $5.7 \%$ o (Fig. 4), in which most of the sampling sites in the two seasons were located in this range.

$\delta^{18} \mathrm{O}-\mathrm{NO}_{3}$ (nitrification) $=1 / 3 \delta^{18} \mathrm{O}-\mathrm{O}_{2}+2 / 3 \delta^{18} \mathrm{O}-\mathrm{H}_{2} \mathrm{O}$ 
$\delta^{16} \mathrm{O}-\mathrm{NO}_{3}$ preferentially under the hypoxic environment (Aechana et al., 2018). Therefore, denitrification would increase $\delta^{15} \mathrm{~N}-\mathrm{NO}_{3}$ and $\delta^{18} \mathrm{O}-\mathrm{NO}_{3}$ value at the same time. Notably, the theoretical denitrification ratio between $\delta^{15} \mathrm{~N}-\mathrm{NO}_{3}$ and $\delta^{18} \mathrm{O}-\mathrm{NO}_{3}$ is 1:1.3 to 1:2 (Divers et al., 2014). However, the denitrification in the Beiyun river was not evident because the DO concentration in the river was beyond $2.0 \mathrm{mg} \mathrm{L}^{-1}$ (Table S4) and the ratio did not meet the theoretical denitrification ratio (Fig. S4). But some weak denitrification potentially occurred in September since $\mathrm{NO}_{3}-\mathrm{N}$ and $\delta^{15} \mathrm{~N}-\mathrm{NO}_{3}$ showed a negative correlation (Fig. S5). This denitrification might occur in submerged subsoil due to the rains in September, and in the riparian or hyporheic zone in the tributaries (Yi et al., 2017). In addition, the Beiyun river mainly received effluent from wastewater treatment plants (Zhang et al., 2020a), and the inflow of external sewage masked the signal of biochemical processes. Overall, a majority of the nitrate in Beiyun River originated from manure \& sewage especially sewage.

Chloride is a stable ideal indicator which can be utilized to evaluate the extra sewage input and biogeochemistry. Its concentration varies only when the surface water is mixed with other sources of water ( $\mathrm{Li}$ et al., 2019). Of note, when $\mathrm{Cl}^{-}$positively correlates with $\mathrm{NO}_{3}-\mathrm{N}$, the $\mathrm{Cl}^{-}$input is mainly influenced by the anthropogenic effect (Yi et al., 2017). The relationship between $\mathrm{Cl}^{-}$and $\mathrm{NO}_{3}-\mathrm{N}$ is highlighted in Fig. 5. During the wet season, the concentration of $\mathrm{Cl}^{-}$and $\mathrm{NO}_{3}-\mathrm{N}$ depicted a positive correlation $\left(R^{2}=0.31\right.$, Fig. 5a). However, in the dry season, a weaker positive correlation was reported compared to the wet season $\left(R^{2}=0.12\right.$, Fig. 5a). Beiyun riverine watershed was not characterized by typical sediment erosion, which had an implication that the $\mathrm{Cl}^{-}$primarily came from sewage, particularly during the wet season.

Manure \& sewage source are, in most cases, characterized by high $\mathrm{Cl}^{-}$ concentration and low $\mathrm{NO}_{3} / \mathrm{Cl}^{-}$molar ratio (Sui et al., 2020). Herein, the ratio of 
$\mathrm{NO}_{3} / \mathrm{Cl}^{-}$in the wet season was lower than that in the dry season (Fig. $5 \mathrm{~b}$ and $\mathrm{S} 6$.), which implied that the manure \& sewage mainly came from the wet season. Moreover, the molar ratio of $\mathrm{NO}_{3} / \mathrm{Cl}^{-}$potentially reduced as the denitrification eliminated nitrates $(\mathrm{Lu}$ et al., 2015) or the nutrients in the water are absorbed by plants (Liu et al., 2019). As highlighted in Fig. S6, weak denitrification occurred in the wet season. Importantly, the concentration of the $\mathrm{Cl}^{-}$was negatively correlated with $\mathrm{NO}_{3} / \mathrm{Cl}^{-}$molar ratio in both two seasons, which implicated that the wastewater majorly originated from daily residential sewage discharge (Zhao et al., 2019). Also, pollution was more severe in the dry season since this correlation was significant.
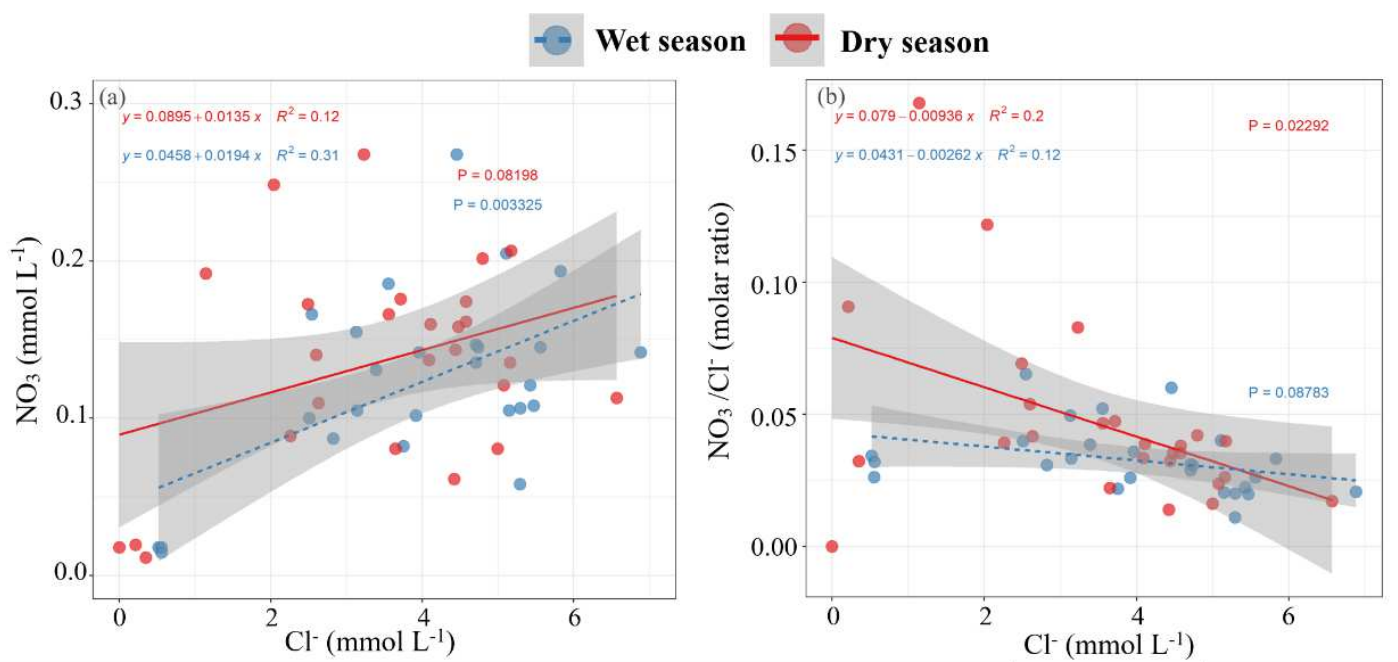

Fig. 5. Cross-plot of (a) $\mathrm{Cl}^{-}$and $\mathrm{NO}_{3}$ molarity. (b) $\mathrm{Cl}^{-}$molarity and $\mathrm{NO}_{3} / \mathrm{Cl}^{-}$molar ratio.

\subsubsection{Source apportionment through statistical analysis}

As mentioned above, the main source of nitrate pollution in the Beiyun riverine watershed was manure \& sewage, but there was still a problem, which was the insignificant difference in nitrate isotope values between the main stream and the tributary caused the unclear source of pollution in manure $\&$ sewage. To obtain a more precise treatment plan, we need to clarify where the manure or sewage in the watershed came from. Therefore, we used cluster analysis combined with hydrochemical indicators and land-use type to explore the specific source of manure \& sewage. In the 
wet season, all sites were classified into 6 clusters (Fig. 6a and S7a.), including cluster I: M6, T10, T18 $\left(\mathrm{NO}_{3}-\mathrm{N}=4.6 \pm 0.7 \mathrm{mg} \mathrm{L}^{-1}\right)$, cluster II: M8, T5, T7 $\left(\mathrm{NO}_{3}-\mathrm{N}=1.1 \pm 0.1 \mathrm{mg}\right.$ $\left.\mathrm{L}^{-1}\right)$, cluster III: $\mathrm{M} 1, \mathrm{M} 2, \mathrm{~T} 2, \mathrm{~T} 8\left(\mathrm{NO}_{3}-\mathrm{N}=5.9 \pm 0.9 \mathrm{mg} \mathrm{L}^{-1}\right)$, cluster IV: T6, T11, T17 $\left(\mathrm{NO}_{3}-\mathrm{N}=10.1 \pm 4.1 \mathrm{mg} \mathrm{L}^{-1}\right)$, cluster $\mathrm{V}: \mathrm{M} 7, \mathrm{~T} 3, \mathrm{~T} 4, \mathrm{~T} 9, \mathrm{~T} 12\left(\mathrm{NO}_{3}-\mathrm{N}=7.9 \pm 2.3 \mathrm{mg} \mathrm{L}^{-1}\right)$ and cluster VI: M3-M5, T1, T13-T16 $\left(\mathrm{NO}_{3}-\mathrm{N}=7.1 \pm 1.2 \mathrm{mg} \mathrm{L}^{-1}\right)$. The sites in clusters IV and $\mathrm{V}$ contributed the most amount of nitrate. These sites were nearly located in the rural-urban fringe areas (land-use proportion: 62.5\%), consisting of the villages and counties away from the urban center. Besides, they had a relatively large population following a report by field sampling and the interpretation of China Population and Employment Statistics Yearbook, 2019 (data.cnki.net). These sites were characterized by serious nitrate pollution because of the daily life practices of the inhabitants, agriculture, and livestock farming (especially in the downstream in Tianjin-Hebei region) during the wet season (Peters et al., 2019), low efficiency of wastewater treatment, and the lack of riverine management (Yi et al., 2017). Therefore, manure \& sewage in these clusters were almost manure from the livestock farming in the wet season. Cluster I and II contributed the least amount of nitrate, and these sites were located in the urban center in the Beijing and Tianjin (urban type land-use proportion: 66.7\%). In these areas, wastewater treatment plants were highly efficient (Xian et al., 2016), as well as the management practices, such as channel cleanout, which was wholesome. Therefore, manure \& sewage in these clusters were almost sewage from WWTPs emissions in the wet season. Sites in cluster VI and III were mainly in the suburban areas within the dry land (suburban type land-use proportion: 66.7\%). These clusters contributed a moderate amount of nitrate and were located in an undeveloped region and they were associated with the complex land-use type. However, from the perspective of individual land-use types, most of the upstream cluster III is close to the 
urban area of Beijing, while the downstream cluster VI is mostly in the center of the suburban areas. Therefore, manure $\&$ sewage in cluster III were almost sewage but in cluster III were almost manure in the wet season. Based on the heatmap (Fig. S7c.), most of the sites in the suburban area, urban area, and rural-urban fringe did not show apparent similarities, which means nitrate sources were complex in the wet season $(\mathrm{Hu}$ et al., 2019).

Similar to the wet season, the sites in the dry season were classified into 4 clusters (Fig. 6b and S7b.), including cluster I: M8, T5, T7 $\left(\mathrm{NO}_{3}-\mathrm{N}=1.0 \pm 0.2 \mathrm{mg} \mathrm{L}^{-1}\right)$, cluster II: M1, M3, T3, T4, T6, T8-T12 ( $\left.\mathrm{NO}_{3}-\mathrm{N}=10.8 \pm 1.8 \mathrm{mg} \mathrm{L}^{-1}\right)$, cluster III: T1, T13, T14, T17 $\left(\mathrm{NO}_{3}-\mathrm{N}=7.0 \pm 1.8 \mathrm{mg} \mathrm{L}^{-1}\right)$, and cluster IV: M2, M4-M7, T2, T15, T16, T18 $\left(\mathrm{NO}_{3}{ }^{-}\right.$ $\left.\mathrm{N}=8.6 \pm 1.1 \mathrm{mg} \mathrm{L}^{-1}\right)$. Sites in cluster II contributed the most amount of nitrate, which were located in the urban fringes (land-use proportion: 60.0\%). Due to the daily life in the dry season, manure \& sewage in this cluster was almost sewage from residential and WWTPs emissions in the dry season. Cluster III and IV ranked second after Cluster II, and these sites were mainly located in the suburban areas (land-use proportion: 69.2\%). And manure \& sewage in this cluster was almost sewage from residential emissions because the livestock farming behavior became less frequent than the wet season. Cluster I provided the least amount of nitrate, and these sites were located in the urban center (land-use proportion: 100\%) thus nitrate came from the sewage in WWTPs emissions. Based on the heatmap (Fig. S7d.), all sites exhibited significant similarity except for sites in the urban areas (T5, T7, and M8 in the urban center). In the dry season, the flow of the river was lower than in the wet season (Peters et al., 2019); also human activities were simplex. Therefore, pollution was severe in the dry season (Liu et al., 2018), and most sites had a similar pollution source which was sewage from residential emissions. 


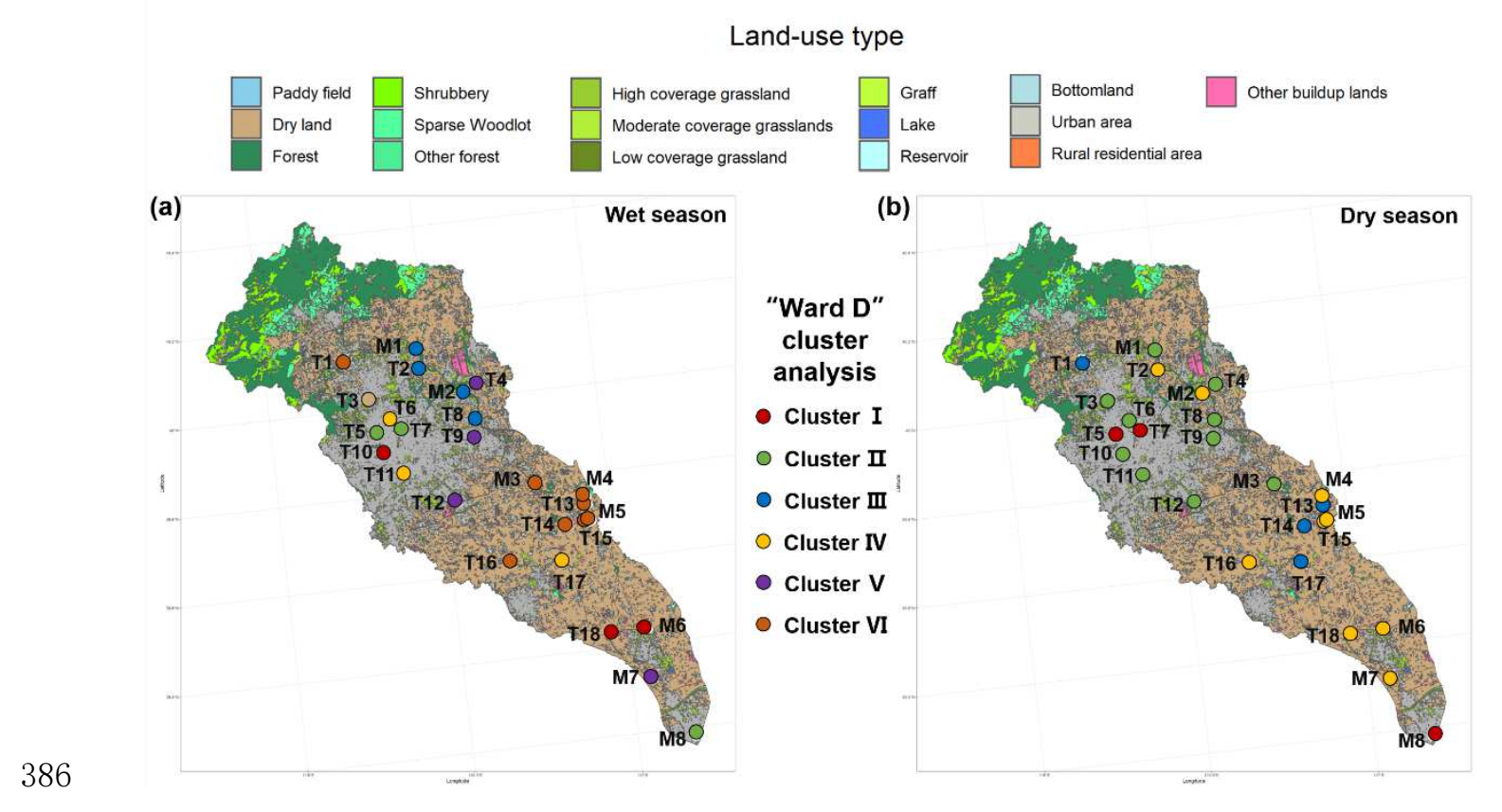

Fig. 6. Cluster map in the (a) wet season and (b) dry season.

\subsection{Contributive proportion of different nitrate sources}

The contributions of each nitrate source in all seasons were estimated via the SIAR model (Fig. 7). In the wet season, manure \& sewage contributed most of the riverine nitrate, and the mean probability estimate (MPE) was $89.6 \%$. They were followed closely by soil nitrogen (5.9\%), nitrogen fertilizer (4.9\%), and atmospheric deposition $(0.6 \%)$. Compared to the wet season, the contribution of manure \& sewage source increased slightly (MPE from $89.6 \%$ to $91.6 \%$ ) in the dry season. Besides, the contributions of nitrogen fertilizer and soil nitrogen decreased (4.9\% to $3.3 \%$, and $5.9 \%$ to $3.9 \%$, respectively), indicating that fertilizer usage and soil erosion reduced due to the low temperature and less amount of rainfall (Peters et al., 2019). The SIAR model showed that the contribution of manure \& sewage was dominant. Also, it proved that daily human activities were the primary source of nitrate. However, the contributions of soil nitrogen and nitrogen fertilizer were relatively lower. Of note, the contribution

401 of atmospheric deposition source was the least in all the seasons, which was consistent with other watersheds (Kruk et al., 2020). In this study, the sampling events occurred 
in one year. The nitrate source may be associated with the dynamic changes which are unexplainable using a one-year sampling. Moreover, climatic conditions, human activities, and nitrate concentrations in water samples differed between the wet and dry seasons (Yi et al., 2017). Therefore, long-term observation or multielement sampling would better identify different contributions and demonstrate the dynamic change process of nitrate sources in the watershed (Hu et al., 2019). In this study, we explained this dynamic change process from the aspect of different land-use types.

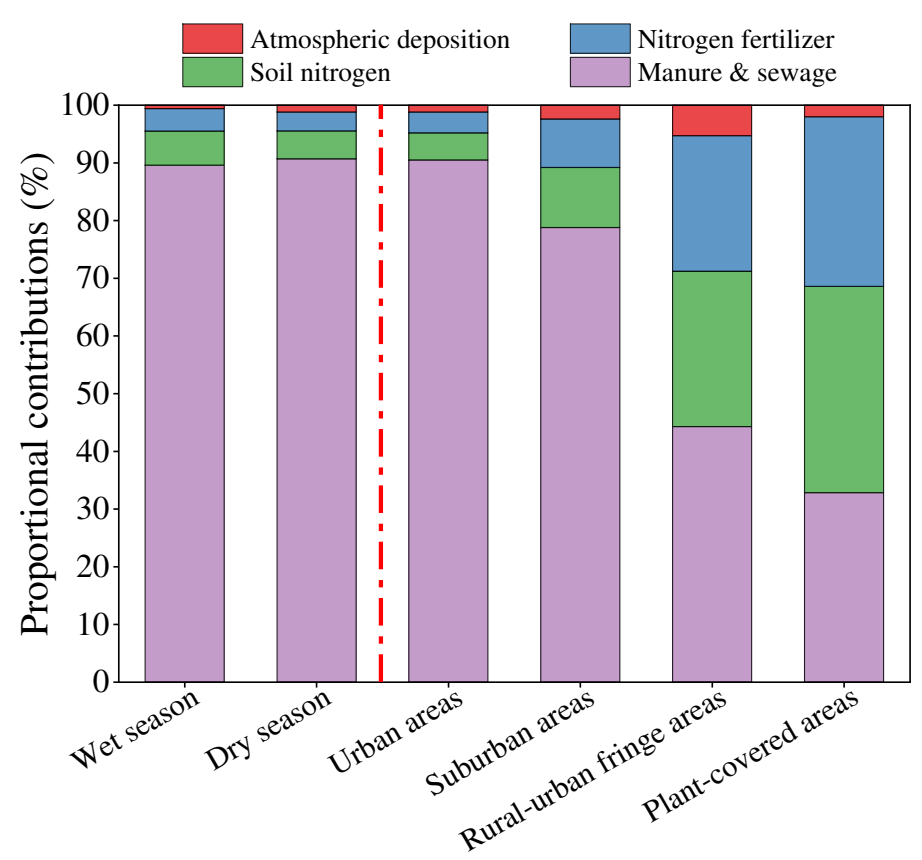

Fig. 7. The contribution rates of four potential nitrate sources at (a) different sampling periods and (b) different land-use types.

To distinguish the nitrate sources in different land-use areas, we classified the respective watershed into four categories: Urban areas, suburban areas, the rural-urban fringe areas, and plant-covered areas. The contributions of each nitrate source in the four land-use types are presented in Fig. 7. Different regions showed different source apportionment patterns. In the urban areas, manure \& sewage contributed the most to the nitrate sources $(90.5 \%)$, followed by soil nitrogen $(4.7 \%)$, nitrogen fertilizer $(3.6 \%)$, 
and atmospheric deposition (1.2\%). Urban areas probably had intensive human activities, thus, the proportion of manure \& sewage discharged was relatively high (Archana et al., 2018). A few investigations showed that the leaking of sewers and the rainfall-runoff were also dominantly linked to urban nitrate pollution (Divers et al., 2013; Hale et al., 2014). This pollution usually resulted from the roof, road, and greenbelt in a dead-end of urban pollution prevention and control. Therefore, except for the control of direct sewage discharge, the management of these dead-end should be given more attention in future assessments. In the suburban areas, the highest nitrate contributor was manure $\&$ sewage $(78.8 \%)$, followed by soil nitrogen $(10.4 \%)$, nitrogen fertilizer (8.4\%), and atmospheric deposition (2.4\%). The high manure \& sewage ratio could be attributed to a large amount of incomplete treatment wastewater released into the river, revealing poor riverine management in suburban areas (Yi et al., 2017). In rural-urban fringe areas, manure \& sewage contributed the most of nitrate (44.3\%), the MPE of soil nitrogen and nitrogen fertilizer was $26.9 \%$ and $23.5 \%$, respectively. In these areas, the population composition and human activities were complex (Yi et al., 2017). Also, the daily life of the residents contributed to most of the nitrate. The lack of proper environmental management may be associated with soil erosion (Lu et al., 2015) and irregular use of fertilizers (Li et al., 2019). The plant-covered areas highly contributed to soil nitrogen among the four land-use types (35.7\%), followed by manure \& sewage (32.8\%), nitrogen fertilizer (29.4\%), and atmospheric deposition (2.0\%). The ratio of fertilizer and sewage inputs due to human activities were limited in these areas (Lu et al., 2015). The above results showed that different land-use types are nitrate sources. Among them, nitrate in densely populated areas mainly originated from sewage. In the untraversed areas such as plant-covered areas, nitrate was mainly derived from soil nitrogen. This finding provides a basis for nitrate control in the complex 
watershed.

\subsection{Comparison of the nitrate source with other twenty-five}

\section{similar watersheds}

The nitrate source would show dynamic variation with the changing human activities and time sequences. The difference in the land-use structure was associated with different development levels and climate change, as a result, the nitrate source varied among different watersheds. Therefore, the quantitative comparison results among watersheds could be used as data support to predict the nitrate source. Notably, there was almost no $\delta^{15} \mathrm{~N}_{-} \mathrm{NO}_{3}$ in the range of atmospheric deposition through the literature screening in the meta-analysis. Therefore, the final result was obtained based on the source of nitrogen fertilizer, soil nitrogen, and manure, and sewage. The contourenhanced funnel chart demonstrated that except for atmospheric deposition, the literature reports on three sources were not associated with publication bias (Fig. S3).

The $\ln (\mathrm{RR})$ values at different climate and land-use types are shown in Fig. 8. The $\ln (\mathrm{RR})$ values of nitrogen fertilizer, soil nitrogen and manure, and sewage in the temperate continental monsoon climate were $0.19,0.01$, and -0.06 , respectively. At the same time, the values of these sources in the non-temperate continental monsoon climate (close to subtropical monsoon climate) were $-0.23,0.09$, and 0.12 , respectively. The positive $\ln (\mathrm{RR})$ value indicated that the corresponding source was the main contributing source of nitrate and vice versa. For the nitrogen fertilizer source, the $\ln (\mathrm{RR})$ value in the temperate continental monsoon climate was 0.42 , which was higher than that of the non-temperate continental monsoon climate. Thus, we concluded that nitrogen fertilizer was the major source in the temperate continental monsoon climate. The watersheds in a temperate continental monsoon climate are more beneficial in developing dryland agriculture. For instance, nitrogen fertilizer was the primary nitrate 
source of nitrate due to the use of nitrogen fertilizer in the North China and West Canada (Bu et al., 2017; Peters et al., 2019; Kruk et al., 2020). While in South China and North Malaysia (Hu et al., 2019; Fadhullah et al., 2020), nitrogen fertilizer was not the primary source of nitrate. For the soil nitrogen source, the $\ln (\mathrm{RR})$ value in the non-temperate continental monsoon climate was 0.08 , higher than that of the temperate continental monsoon climate, an implication that soil nitrogen was the primary source in the nontemperate continental monsoon climate. The subtropical monsoon climate experience adequate rainfall, which might accelerate soil erosion. At the same time, paddy agriculture was an important reason that contributes to soil erosion in this climate type. This observation concurred with the results from the Xijiang River in China (Li et al., 2019) and the peninsular in Malaysia (Fadhullah et al., 2020), which contributed to more than $35 \%$ among the four sources. Moreover, the $\ln (\mathrm{RR})$ value of manure $\&$ sewage in the non-temperate continental monsoon climate was 0.18 , higher than that of the temperate continental monsoon climate. This implicated manure \& sewage as the primary source in the non-temperate continental monsoon climate. Of note, because of multiple population composition and high-density population distribution (Fig. S8), human activities in non-temperate continental monsoon climate were more complicated than temperate continental monsoon climate. A large amount of artificial sewage was also applied in this area. Previous studies showed that the contribution of manure \& sewage to nitrate source could reach up to $90 \%$ in the non-temperate continental monsoon climate and densely populated area (e.g., Taihu Lake watershed, Panxi river) (Zhang et al., 2015; Yi et al., 2017).

In addition, the land-use type is an essential factor affecting the source of nitrate (Lu et al., 2015; Hu et al., 2019a). The $\ln (\mathrm{RR})$ values of nitrogen fertilizer, soil nitrogen and manure, and sewage in the complex urban and rural areas were 0.02, 0.09, and 0.03, 
respectively. While the values of these sources in the non-complex urban and rural environment (almost agricultural land) were $0.21,-0.25$, and -0.13 , respectively. For the nitrogen fertilizer source, the $\ln (\mathrm{RR})$ value in the non-complex urban and rural areas was 0.19 , higher than that of the complex urban and rural areas. Thus, these two landuse types, nitrogen fertilizer was the primary source in non-complex urban and rural areas due to advanced agricultural systems in these areas (Li et al., 2014b; Peters et al., 2019). For the soil nitrogen source, the $\ln (\mathrm{RR})$ value in the complex urban and rural areas was 0.34 , higher than that of the non-complex urban and rural areas. Therefore, in these two land-use types, soil nitrogen was the primary source in the complex urban and rural areas. In the sophisticated urban and rural areas, soil erosion was caused by agriculture irrigation activities (Yi et al., 2017), urban rainwater runoff (Yang and Toor, 2016), and sewer leaks (Divers et al., 2014) at the same time. The single agricultural land contributed less to nitrate from soil nitrogen. Soil nitrogen accounted for only $25 \%$ of the four sources in a recent study on the Huaihe River (Ma et al., 2019).

Moreover, the $\ln (\mathrm{RR})$ value of manure \& sewage in the complex urban and rural areas was 0.16 higher than that of the non-complex urban and rural areas. Thus, we suggested that in these two land-use types, manure \& sewage was the primary source in the complex urban and rural areas. Complex urban and rural areas had complex population composition and intensive population density, which led to the most artificial pollution. Moreover, manure \& sewage in these areas could generally contribute more than $80 \%$ of nitrate (Yi et al., 2017; Liu et al., 2018). According to the comparison results among the Beiyun riverine watershed and other similar watersheds, nitrate mainly was derived from nitrogen fertilizer and soil nitrogen. Similarly, the amount of nitrate in manure \& sewage continuously rose with the progression of future urbanization and the increase in human activities. 


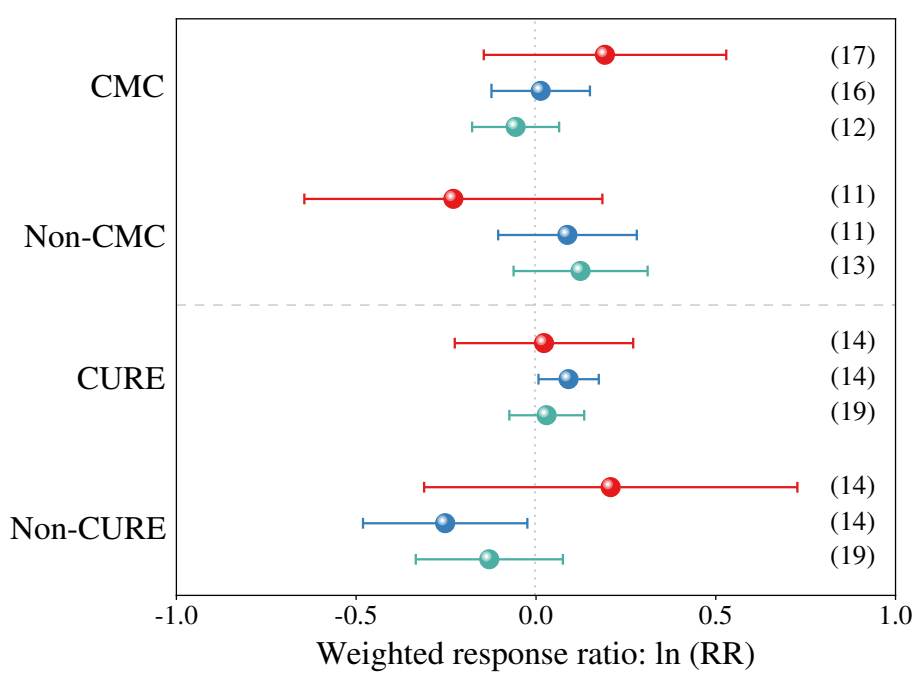

CMC: Temperate continental monsoon climate

- Nitrogen fertilizer

CURE: Complex urban and rural environment

- Soil nitrogen

- Manure \& sewage

Fig. 8. The weighted response ratios $\ln (R R)$ of climate type, land-use type, and different sources of nitrate. The solid dots are the mean value of $\ln (\mathrm{RR})$, the straight line is $95 \%$ confidence intervals, and the sample size is in parentheses.

\section{Conclusion}

This study adopted the nitrate dual isotopes technique integrated with hydrochemical index and statistical methods to trace the nitrate in the Beiyun riverine watershed. Based on the findings, nitrate was revealed to be the main form of nitrogen pollution in the watershed, and it was more massive in the dry season. For the nitrate source apportionment, nitrate in the wet season mainly originated from the rural-urban fringe area in the Tianjin-Hebei region. On the contrary, nitrate came from the ruralurban fringe area in the Beijing-Hebei region in the dry season. At the same time, the SIAR model showed that manure \& sewage were the primary sources in both two seasons, reaching $89.6 \%$ and $91.6 \%$. Moreover, for different land-use types, manure $\&$ sewage was recorded at $90.5 \%, 78.8 \%, 44.3 \%$, and $32.8 \%$ in urban areas, suburban areas, the rural-urban fringe areas, and plant-covered areas, respectively. Through a meta-analysis, the Beiyun riverine watershed, located in a region with a temperate 
continental monsoon climate, was characterized by complex land-use types. Nitrate originated not only from human sewage but also from soil nitrogen and nitrogen fertilizer, especially $\mathrm{NH}_{4}$-fertilizer in the big picture. This study provides insights into the prevention and control of nitrate in the Beijing-Tianjin-Hebei region. In the future, taking into accounting the spatiotemporal variations of nitrate sources and the relationship with the isotopic composition of nitrate, watershed restoration and management strategies need to consider the potential for major changes in the source due to changes in climate and hydrological conditions. As a long-term strategy, it is possible to regulate the agriculture and livestock farming in downstream of the watershed, to improve the nitrogen fixation capacity of the soil on both sides of the river, and appropriately reduce the direct discharge of WWTPs to the river. Such an approach will also of great significance to improve the denitrification potential of nitrate in the watershed. However, in this study, some small-micro water bodies had dried up for a long time, so the source of them had not been traced. Therefore, it is recommended that these water bodies should be considered for nitrate trace or water source investigation in future assessments.

\section{Ethical Approval}

$$
\text { Not Applicable }
$$

\section{Consent to Participate}

Not Applicable

\section{Consent to Publish}

Not Applicable

\section{Authors Contributions}

Zuhong Lin: Experiment, Software, Writing- Original draft preparation. 
Junchi Liu: Experiment, Data curation, Editing. Yong Xiao: Funding acquisition, Supervision

\section{Funding}

This work was financially supported by the Major Science and Technology Program for Water Pollution Control and Treatment (No. 2018ZX07111003) and the National Natural Science Foundation of China (No. 41977142).

\section{Competing Interests}

The authors declare that they have no competing interests

\section{Availability of data and materials}

All data is provided in full in the results section of this manuscript.

\section{Reference}

Archana A., Thibodeau B., Geeraert N., Xu M., Kao S., Baker D., 2018. Nitrogen sources and cycling revealed by dual isotopes of nitrate in a complex urbanized environment. Water Research. 142, 459-470.

Bu H., Song X., Zhang Y., Meng W., 2017. Sources and fate of nitrate in the Haicheng River basin in Northeast China using stable isotopes of nitrate. Ecological Engineering. 98, 105-113.

Divers M., Elliott E., Bain D., 2013. Constraining nitrogen inputs to urban streams from leaking sewers using inverse modeling: Implications for dissolved inorganic nitrogen (DIN) retention in urban environments. Environmental Science \& Technology. 47(4), 
Divers M., Elliott E., Bain D., 2014. Quantification of nitrate sources to an urban stream using dual nitrate isotopes. Environmental Science \& Technology. 48(18), 10580and processes in the surface water of a tropical reservoir by stable isotopes and mixing model. Science of the Total Environment. 700, 134517.

Hale R., Turnbull L., Earl S., Grimm N., Riha K., Michalski G., Lohse K., Childers D., 2014. Sources and transport of nitrogen in arid urban watersheds. Environmental Science \& Technology. 48(11), 6211-6219.

Hu M., Liu Y., Zhang Y., Dahlgren R., Chen D., 2019. Coupling stable isotopes and water chemistry to assess the role of hydrological and biogeochemical processes on riverine nitrogen sources. Water Research. 150, 418-430.

Jackson A., Inger R., Bearhop S., Parnell A., 2009. Erroneous behaviour of MixSIR, a recently published Bayesian isotope mixing model: a discussion of Moore \& Semmens. Ecology Letters. 12(3), 1-5.

Jani J., Toor G., 2018. Composition, sources, and bioavailability of nitrogen in a longitudinal gradient from freshwater to estuarine waters. Water Research. 137, 344354.

Jiang H., Zhang Q. Q., Liu W.J., Zhang J. Y., Pan K., Zhao T., Xu Z. F., 2021. Isotopic compositions reveal the driving forces of high nitrate level in an urban river: Implications for pollution control. Journal of Cleaner Production. 298, 126693- 
Kruk M., Mayer B., Nightingale M., Laceby J., 2020. Tracing nitrate sources with a combined isotope approach $\left(\operatorname{delta}(15) \mathrm{NNO}_{3}\right.$, delta(18) $\mathrm{ONO}_{3}$ and $\left.\operatorname{delta}(11) \mathrm{B}\right)$ in a large mixed-use watershed in southern Alberta, Canada. Science of the Total Environment. 703, 135043.

Li C., Jiang Y., Guo X., Cao Y., Ji H., 2014a. Multi-isotope ((15)N, (18)O and (13)C)

611 indicators of sources and fate of nitrate in the upper stream of Chaobai River, Beijing,

612 China. Environmental Science-Processes \& Impacts. 16(11), 2644-2655.

Li C., Li S., Yue F., Liu J., Zhong J., Yan Z., Zhang R., Wang Z., Xu S., 2019. Identification of sources and transformations of nitrate in the Xijiang River using nitrate isotopes and Bayesian model. Science of the Total Environment. 646, 801810.

Li X., Liu C., Liu X., Yu J., Liu X., 2014b. Sources and processes affecting nitrate in a dam-controlled subtropical river, Southwest China. Aquatic Geochemistry. 20(5),

Liu J., Shen Z., Yan T., Yang Y., 2018. Source identification and impact of landscape pattern on riverine nitrogen pollution in a typical urbanized watershed, Beijing, China. Science of the Total Environment. 628-629, 1296-1307.

Liu Y., Wang X., Wen Q., Zhu N., 2019. Identifying sources and variations of organic matter in an urban river in Beijing, China using stable isotope analysis. Ecological Indicators. 102, 783-790.

Lu L., Cheng H., Pu X., Liu X., Cheng Q., 2015. Nitrate behaviors and source 
apportionment in an aquatic system from a watershed with intensive agricultural activities. Environmental Science-Processes \& Impacts. 17(1), 131-144.

Ma G., Wang Y., Bao X., Hu Y., Liu Y., He L., Wang T., Meng F., 2015. Nitrogen pollution characteristics and source analysis using the stable isotope tracing method in Ashi River, northeast China. Environmental Earth Sciences. 73(8), 4831-4839.

Ma P., Liu S., Yu Q., Li X., Han X., 2019. Sources and transformations of anthropogenic nitrogen in the highly disturbed Huai River Basin, Eastern China. Environmental Science and Pollution Research. 26(11), 11153-11169.

Parnell A., Inger R., Bearhop S., Jackson A., 2010. Source partitioning using stable isotopes: coping with too much variation. PLoS One. 5(3), 9672.

Peters M., Guo Q., Strauss H., Wei R., Li S., Yue F., 2019. Contamination patterns in river water from rural Beijing: A hydrochemical and multiple stable isotope study. Science of the Total Environment. 654, 226-236.

Shin W., Ryu J., Lee K., Chung G., 2013. Seasonal and spatial variations in water chemistry and nitrate sources in six major Korean rivers. Environmental Earth Sciences. 68(8): 2271-2279.

Silva S., Kendall C., Wilkison D., Ziegler A., Chang C., Avanzino R., 2000. A new method for collection of nitrate from fresh water and the analysis of nitrogen and oxygen isotope ratios. Journal of Hydrology. 228(1), 22-36.

Sui Y. Y., Qu Y., Yan B.X., Rousseau A. N., Fang Y. T., Geng R. Z., Wang L. X., Ye N., 2020. A dual isotopic framework for identifying nitrate sources in surface runoff in a small agricultural watershed, northeast China. Journal of Cleaner Production, 246, 
650

651

652

653

654

655

656

657

658

659

660

661

662

663

664

665

666

667

668

669

670

Wang Z. J., Xu M. M., Wang Y. H., Wang T., Wu N., Zheng W. J., Duan H. W., 2021. Air particulate matter pollution and circulating surfactant protein: A systemic review and meta-analysis. Chemosphere 272, 129564-129572.

Wu W., Liao R., Hu Y., Wang H., Liu H., Yin S., 2020. Quantitative assessment of groundwater pollution risk in reclaimed water irrigation areas of northern China. Environmental Pollution. 261, 114173.

Xian C., Ouyang Z., Li Y., Xiao Y., Ren Y., 2016. Variation in nitrate isotopic signatures in sewage for source apportionment with urbanization: a case study in Beijing, China. Environmental Science and Pollution Research. 23(22), 22871-22881.

Xing M., Liu W., 2011. An improved method of ion exchange for nitrogen isotope analysis of water nitrate. Analytica Chimica Acta. 686(1-2), 107-114.

Yang Y and Toor G S., 2016. delta(15)N and delta(18)O reveal the sources of nitratenitrogen in urban residential stormwater runoff. Environmental Science \& Technology. 50(6), 2881-2889.

Yi Q., Chen Q., Hu L., Shi W., 2017. Tracking Nitrogen Sources, Transformation, and transport at a basin scale with complex plain river networks. Environmental Science \& Technology. 51(10), 5396-5403.

Zhang C., Wan Z., Jing Z., Zhang S., Zhao Y., 2020a. Calculation of ecological water requirements of urban rivers using a hydrological model: A case study of Beiyun River. Journal of Cleaner Production. 262, 121368.

Zhang H., Kang X., Wang X., Zhang J., Chen G., 2020b. Quantitative identification of 
671 nitrate sources in the surface runoff of three dominant forest types in subtropical 672 China based on Bayesian model. Science of the Total Environment. 703, 135074.

673 Zhang L., You Y., Gao C., Peng Y., Cao Z., 2021. Dissolved organic nitrogen structural 674 and component changes in overlying water along urban river at molecular and 675 material levels - Beiyun basin case study. Journal of Cleaner Production, 287, 125570. 676 Zhang M., Zhi Y., Shi J., Wu L., 2018a. Apportionment and uncertainty analysis of 677 nitrate sources based on the dual isotope approach and a Bayesian isotope mixing 678 model at the watershed scale. Science of the Total Environment. 639, 1175-1187.

679 Zhang Q., Wang X., Sun F., Sun J., Liu J., Ouyang Z., 2015. Assessment of temporal 680 and spatial differences of source apportionment of nitrate in an urban river in China, 681 using delta(15)N and delta(18)O values and an isotope mixing model. Environmental $682 \quad$ Science and Pollution Research. 22(24), 20226-20233.

683 Zhang Y., Shi P., Li F., Wei A., Song J., Ma J., 2018b. Quantification of nitrate sources 684 and fates in rivers in an irrigated agricultural area using environmental isotopes and 685 a Bayesian isotope mixing model. Chemosphere. 208, 493-501.

686 Zhao Y., Zheng B., Jia H., Chen Z., 2019. Determination sources of nitrates into the 687 Three Gorges Reservoir using nitrogen and oxygen isotopes. Science of the Total 688 Environment. 687, 128-136. 


\section{Figures}
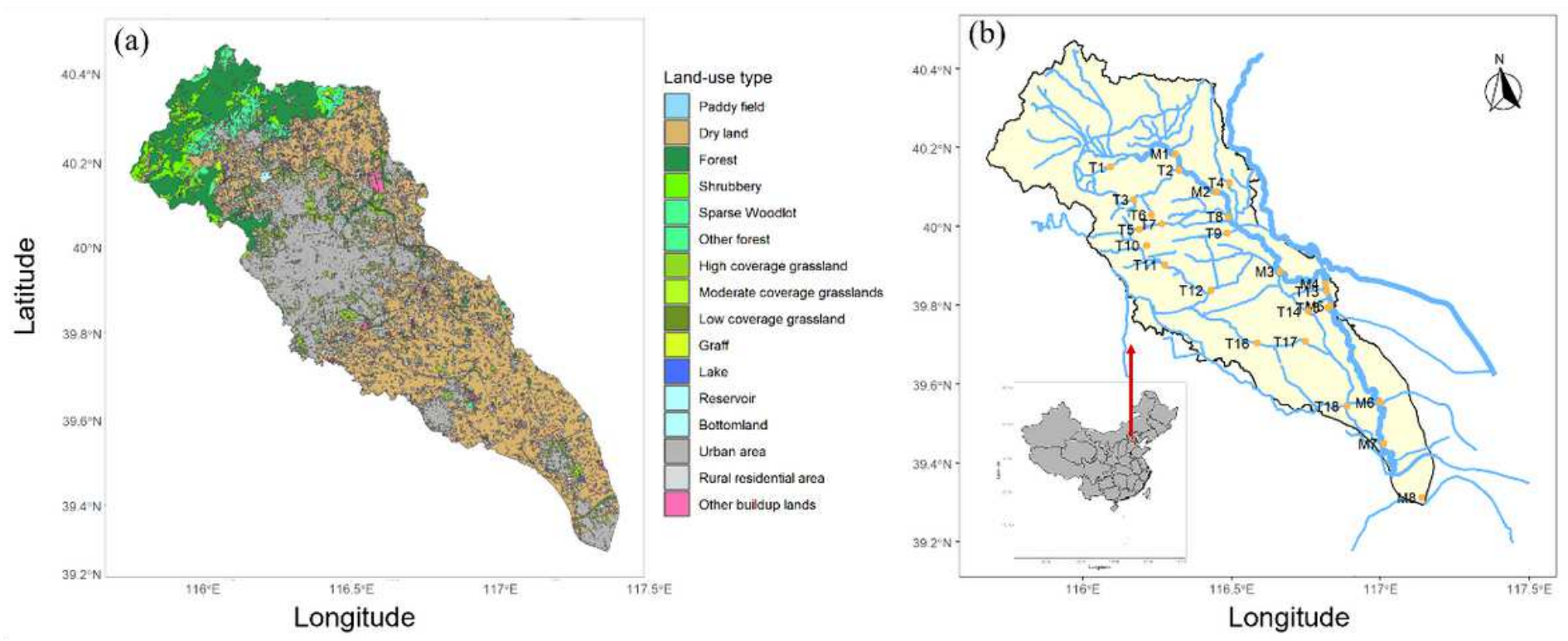

\section{Figure 1}

Study area and sampling sites in the Beiyun riverine watershed. Note: The designations employed and the presentation of the material on this map do not imply the expression of any opinion whatsoever on the part of Research Square concerning the legal status of any country, territory, city or area or of its authorities, or concerning the delimitation of its frontiers or boundaries. This map has been provided by the authors. 

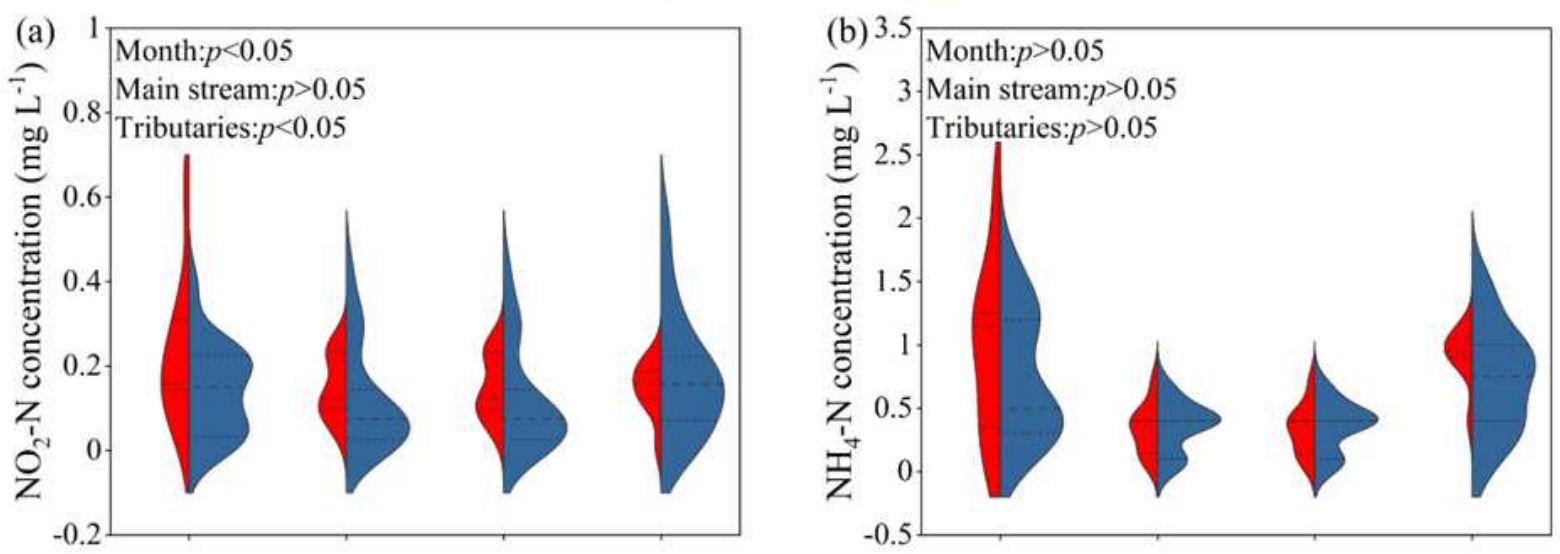

(c) 25 Month:p>0.05

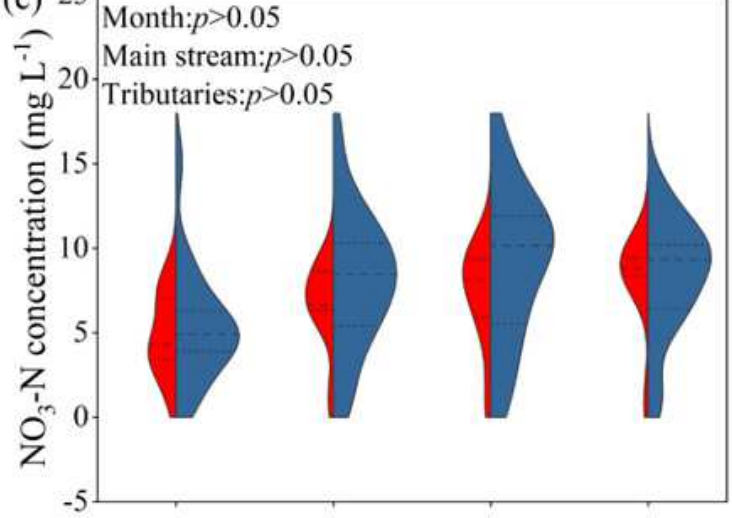

(d) 25 Month: $p>0.05$

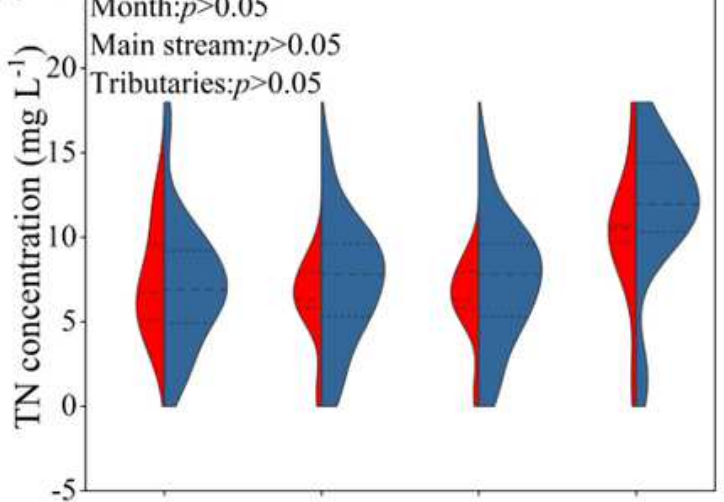

(e) 40 Month: $p>0.05$

35 Main stream: $p>0.05$

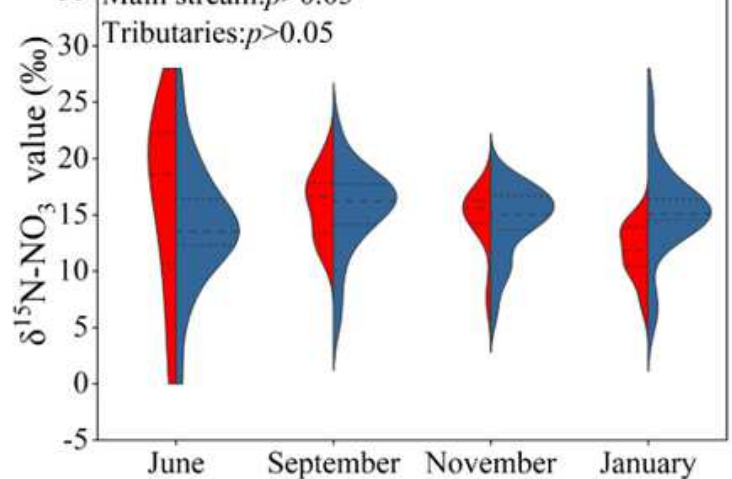

(f) 20 Month: $p>0.05$

15. Main stream: $p>0.05$

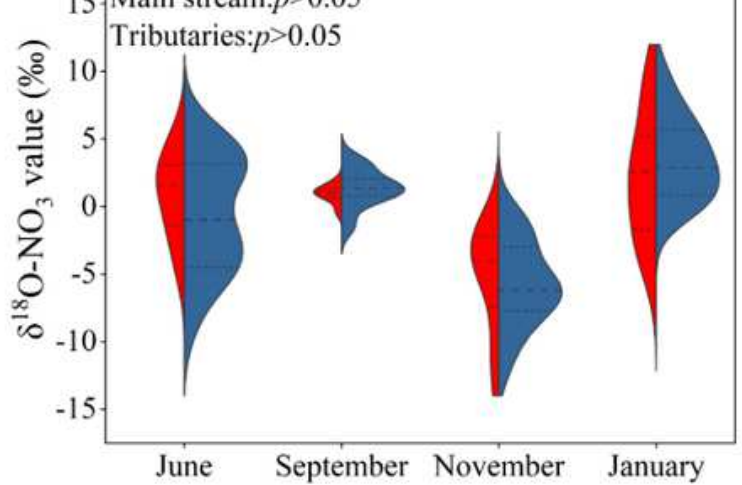

\section{Figure 2}

Spatiotemporal variations of inorganic nitrogen and nitrate isotopes (a) NO2-N (b) NH4-N (c) NO3-N (d) TN (e) $\delta 15 N-N 03$ (f) $\delta 180-N 03$. Dashed are the median line, dotted are the lines of upper and lower quartiles, and the monitoring data points are concentrated in the saturation region of violin plot. 


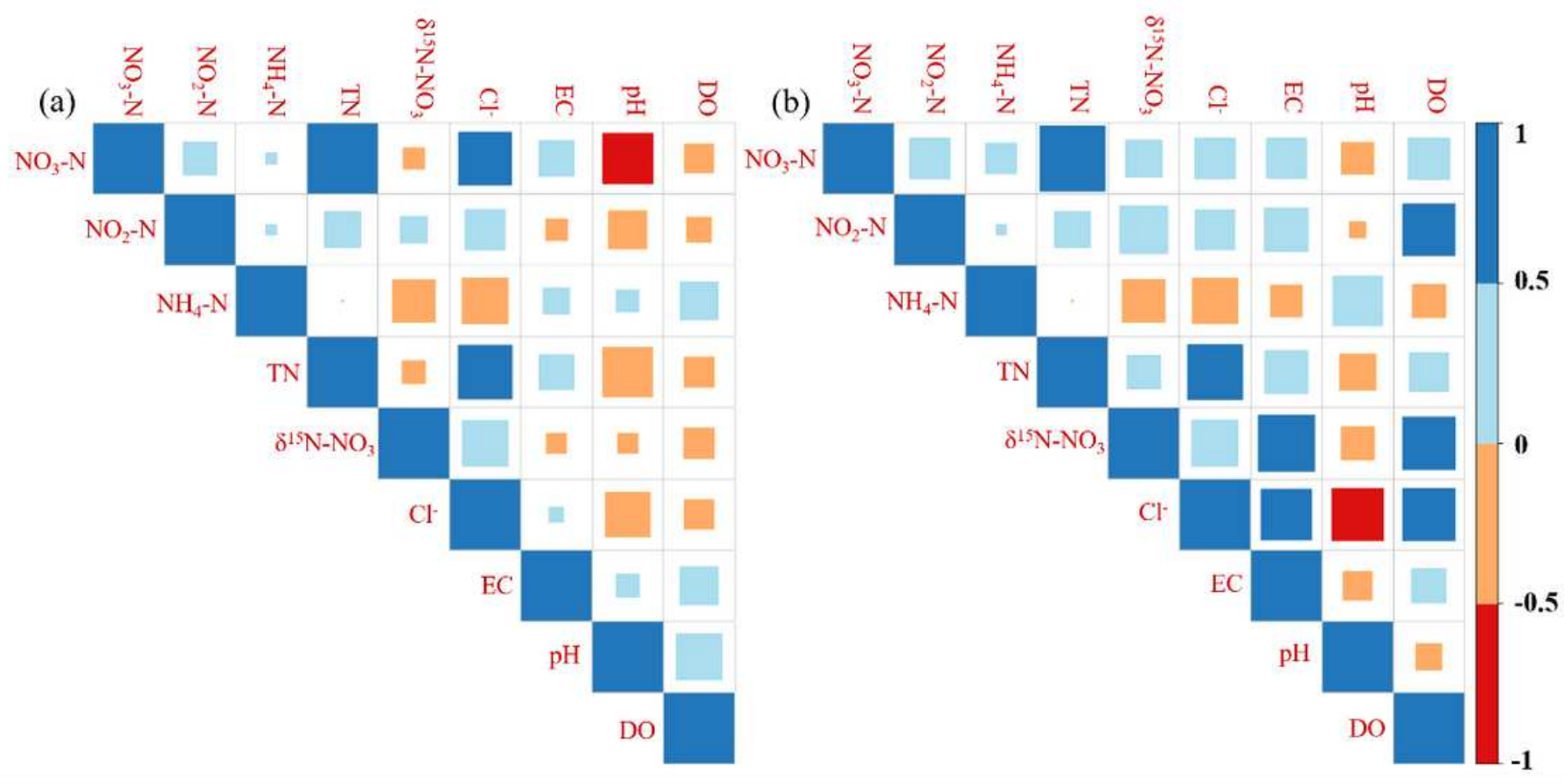

Figure 3

Correlation between nitrate isotopes and hydrochemical indicators in the (a) wet season and (b) dry season. 


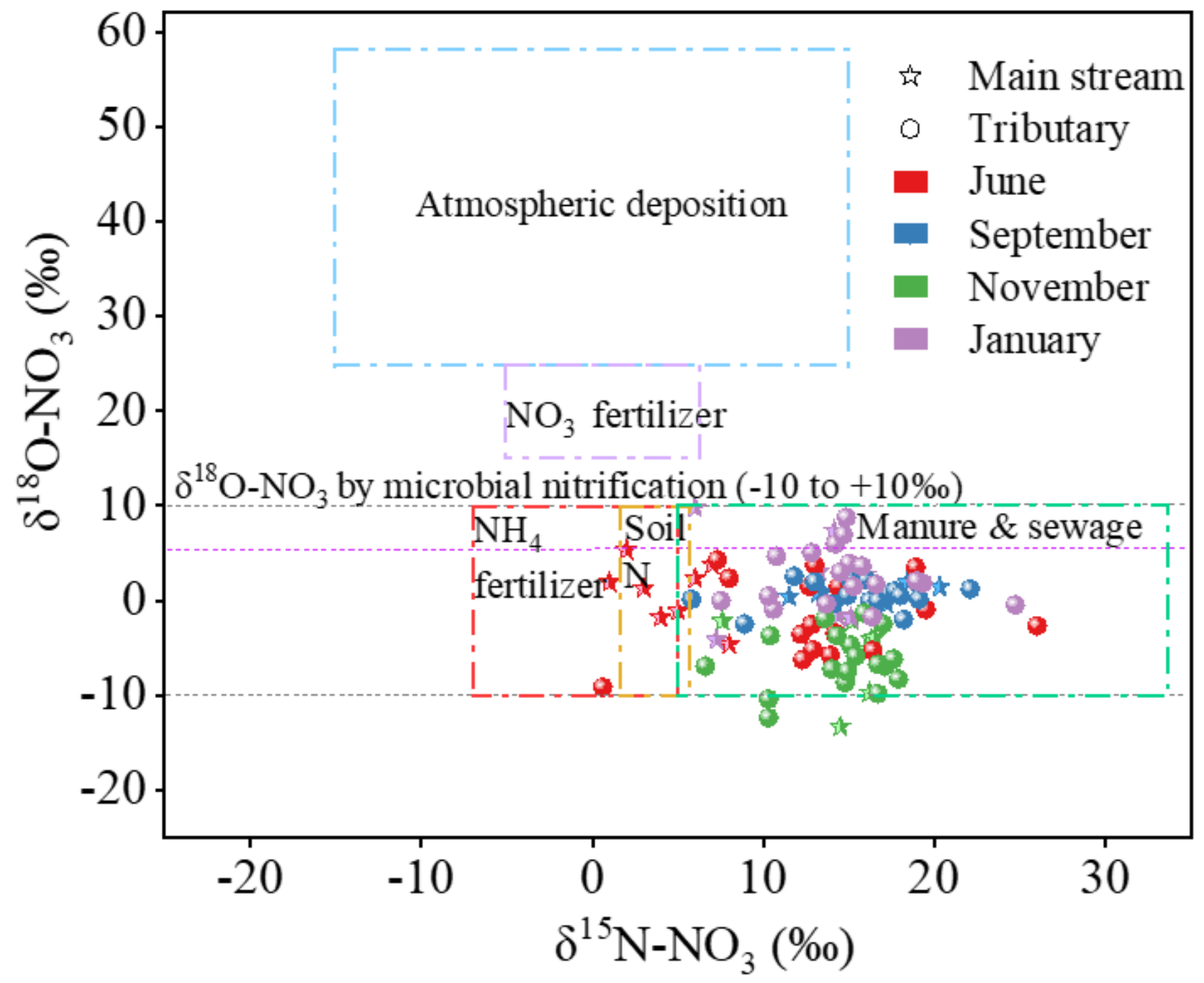

Figure 4

Nitrate isotopic value in the Beiyun river together with typical nitrate isotope source members. The theoretical $8180-\mathrm{NO} 3$ value of nitrification was in the range of $-10 \%$ to $5.7 \%$ ( Li et al., 2014a; Liu et al., 2018). The various nitrate isotope sources in the plot are adapted from previous studies (Shin et al., 2013; Jani and Toor, 2018). 


\section{- Wet season - Dry season}
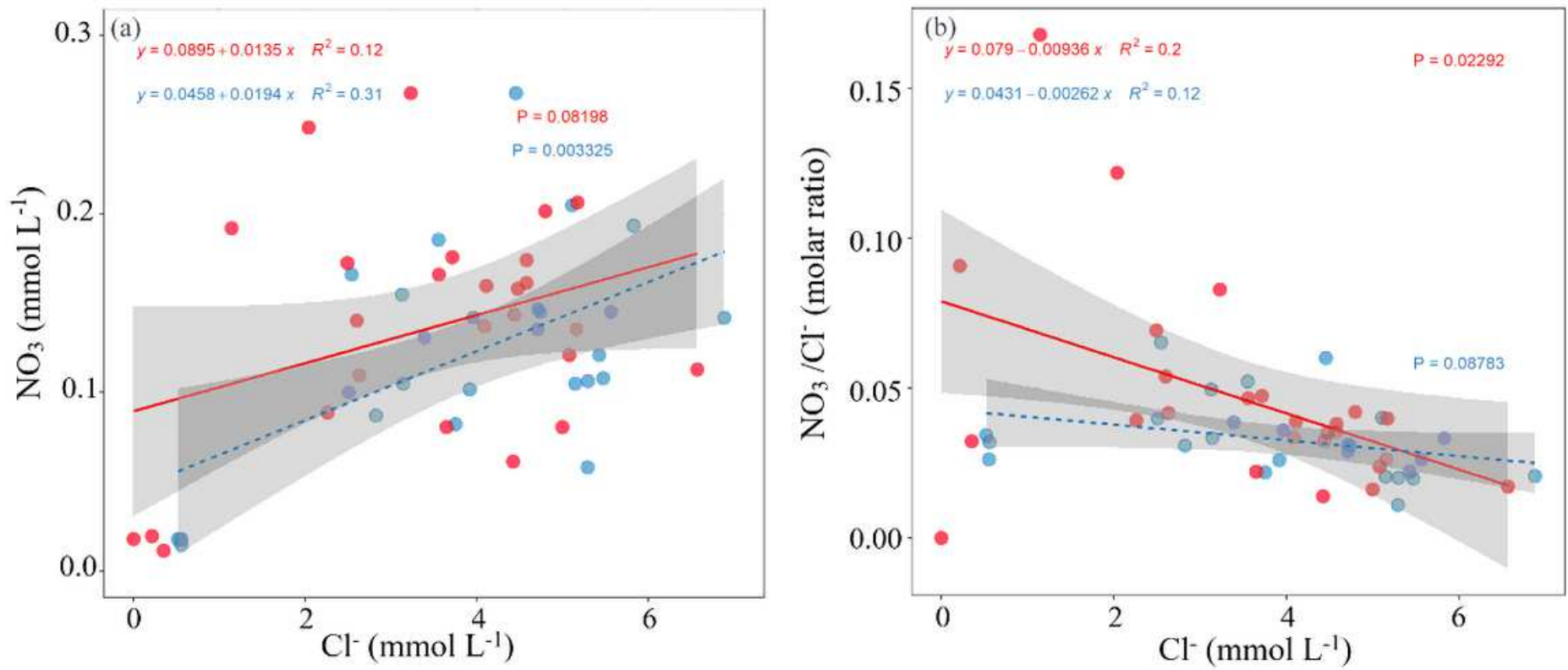

Figure 5

Cross-plot of (a) $\mathrm{Cl}$ - and $\mathrm{NO} 3$ molarity. (b) $\mathrm{Cl}$ - molarity and NO3/Cl- molar ratio. 3.2.2 Source apportionment through statistical analysis

\section{Land-use type}

$\begin{array}{ll}\square \text { Paddy field } \square & \text { Shrubbery } \\ \text { Dry land } & \square \text { Sparse Woodlot } \\ \text { Forest } & \square \\ \text { Other forest }\end{array}$

(a)

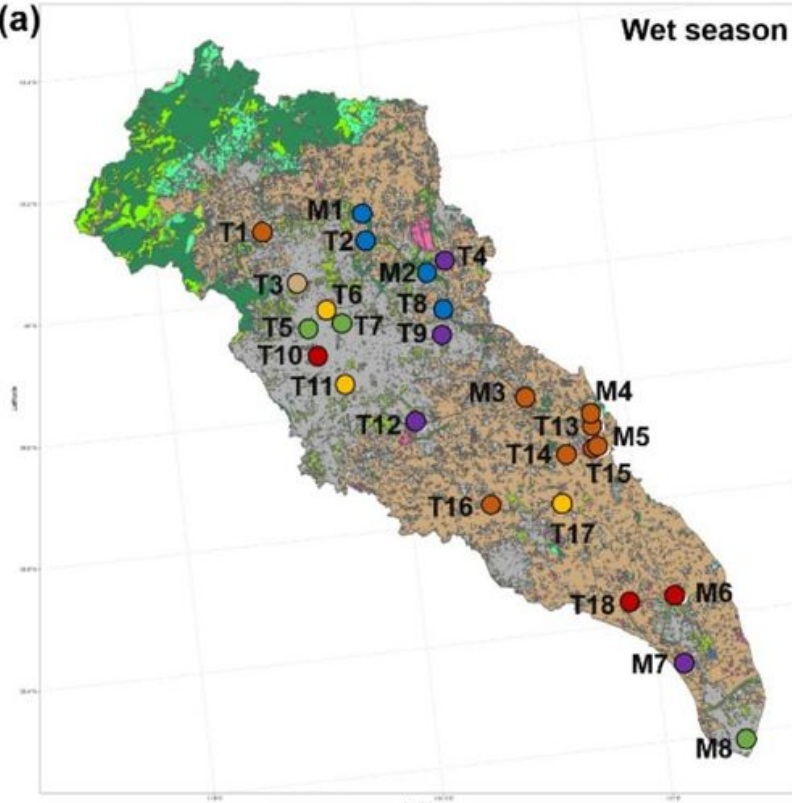

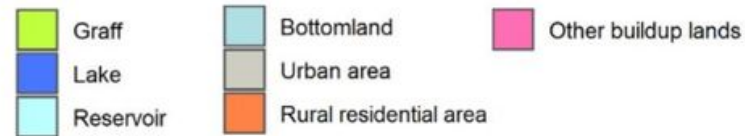

(b)

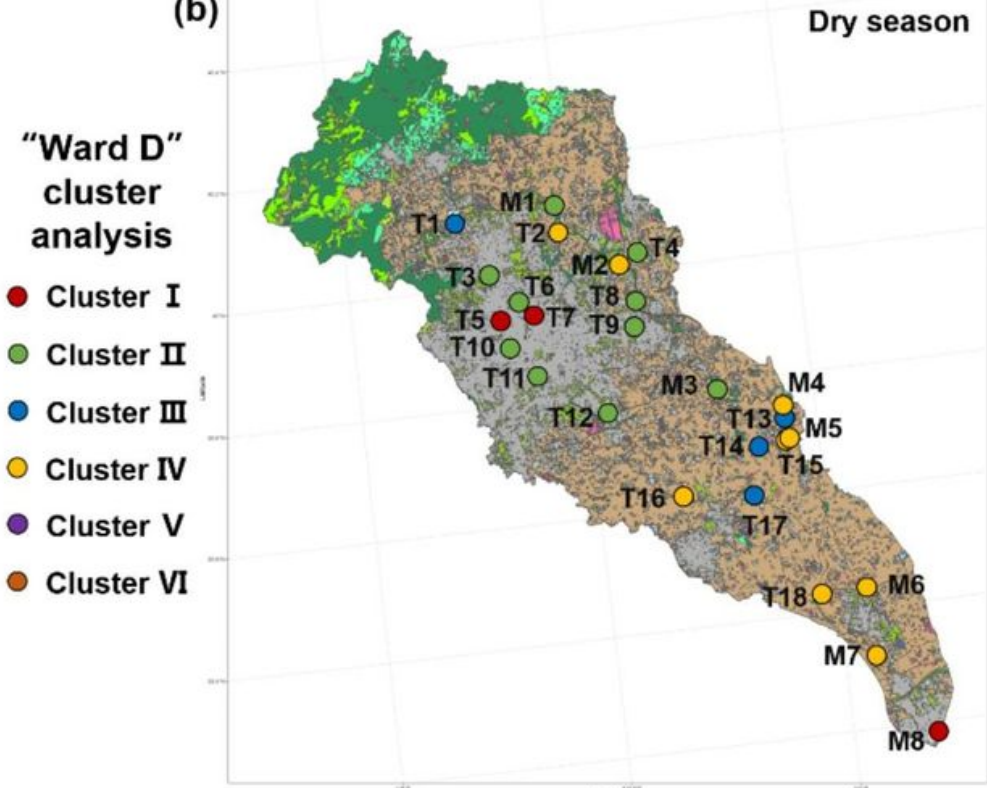


Figure 6

Cluster map in the (a) wet season and (b) dry season. Note: The designations employed and the presentation of the material on this map do not imply the expression of any opinion whatsoever on the part of Research Square concerning the legal status of any country, territory, city or area or of its authorities, or concerning the delimitation of its frontiers or boundaries. This map has been provided by the authors.

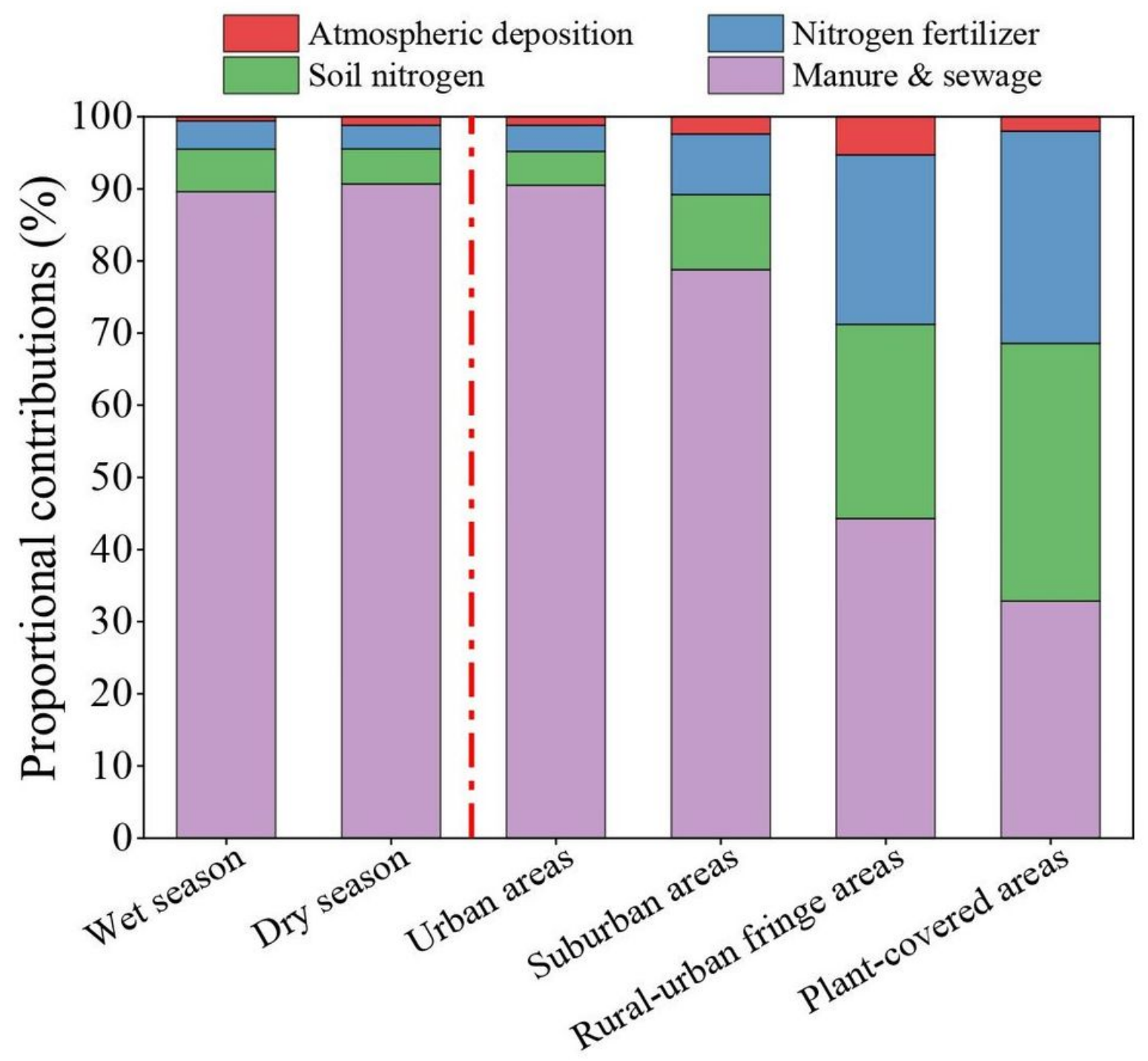

Figure 7

The contribution rates of four potential nitrate sources at (a) different sampling periods and (b) different land-use types. 


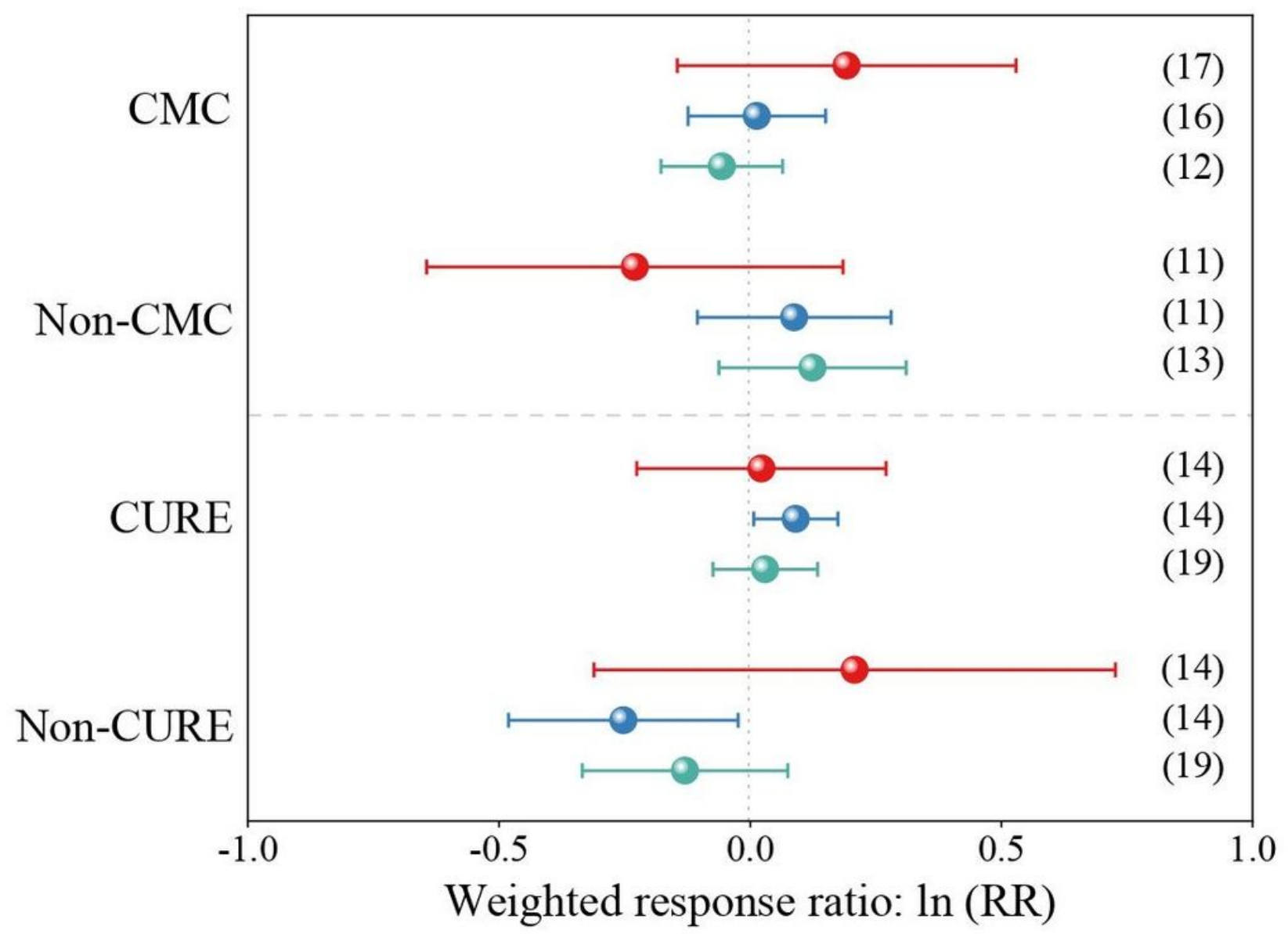

CMC: Temperate continental monsoon climate

Nitrogen fertilizer

CURE: Complex urban and rural environment

Soil nitrogen

Manure \& sewage

\section{Figure 8}

The weighted response ratios $\ln (\mathrm{RR})$ of climate type, land-use type, and different sources of nitrate. The solid dots are the mean value of In (RR), the straight line is $95 \%$ confidence intervals, and the sample size is in parentheses.

\section{Supplementary Files}

This is a list of supplementary files associated with this preprint. Click to download.

- Izh04.23NitrateSupporting.docx 